\title{
AS ROCHAS VULCÂNICAS DA ILHA SÃO JORGE, AÇORES (PORTUGAL): PETROGRAFIA E GEOQUÍMICẢ
}

\author{
THE VOLCANIC ROCKS OF SÃO JORGE ISLAND, AZORES (PORTUGAL): PETROGRAPHY \\ AND GEOCHEMISTRY
}

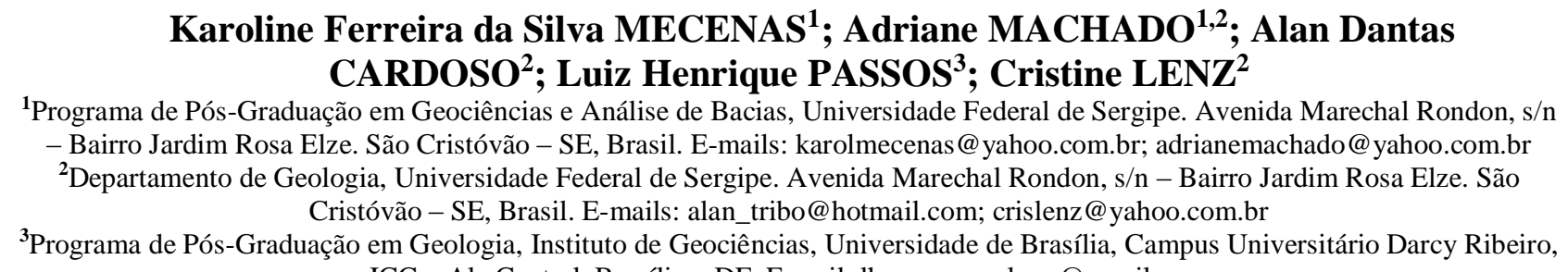
ICC - Ala Central. Brasília - DF. E-mail: lhpassos.geologo@gmail.com

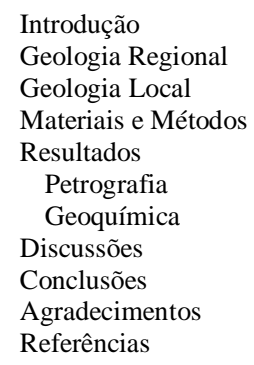

RESUMO - A Ilha São Jorge faz parte do Grupo Central do Arquipélago dos Açores (Portugal), situado próximo à junção tríplice, entre as placas litosféricas Norte-Americana, Euro-Asiática e Africana, na região do Atlântico Norte. A vulcanoestratigrafia da ilha é composta por três complexos vulcânicos denominados Topo, Rosais e Manadas. Segundo a bibliografia, a idade da Ilha São Jorge é $1,309 \pm 0,0035 \mathrm{Ma}\left({ }^{40} \mathrm{Ar} /{ }^{39} \mathrm{Ar}\right)$. Com base na petrografia, as rochas apresentam granulometria média a fina, texturas porfirítica, microporfirítica, glomeroporfirítica, intergranular, pilotaxítica, traquítica e intersertal. De acordo com dados geoquímicos, as rochas foram classificadas como basanitos, basaltos alcalinos e hawaítos, compostos por olivina, augita, plagioclásio e minerais opacos, que ocorrem como fenocristais ou inseridos na matriz. Algumas amostras de basalto alcalino e hawaíto apresentam kaersutita, interpretada como xenocristal. Texturas de reabsorção, embainhamento, zonação e bordas de reação são feições comuns em fenocristais e indicam que o magma sofreu descompressão rápida, com variação brusca de temperatura e pressão. A interpretação geoquímica permitiu concluir que as lavas apresentam afinidade alcalina sódica e foram geradas por baixas taxas de fusão parcial, a partir de uma fonte mantélica enriquecida. Os dados geoquímicos são compatíveis com os de magmas gerados em ambiente geotectônico do tipo intraplaca oceânico (OIB).

Palavras-chave: Basalto de Ilha Oceânica, Arquipélago dos Açores, Ilha São Jorge.

ABSTRACT - The São Jorge Island is part of the Central Group of the Azores Archipelago (Portugal), located near the triple junction, of the North American, Euro-Asian and African lithospheric plates, in the North Atlantic region. The island volcanostratigraphy is composed of three volcanic complexes called Topo, Rosais and Manadas. According to the bibliography, the age of the São Jorge Island is $1.309 \pm 0.0035 \mathrm{Ma}\left({ }^{40} \mathrm{Ar} /{ }^{39} \mathrm{Ar}\right)$. The rocks have medium to fine granulometry, bearing porphyritic, microporphyritic, glomeroporphyritic, intergranular, pilotaxytic, trachytic and intersertal textures. They were chemically classified as basanites, alkaline basalts and hawaiites, composed of olivine, augite, plagioclase and opaque minerals that occur as phenocrysts or inserted in the matrix. Some samples of alkaline basalt and hawaiite show kaersutite, interpreted as a xenocrystal. Reabsorption textures, embayment, zoning and reaction edges are common features in phenocrystals and indicate that the magma underwent rapid decompression, with sudden variation of temperature and pressure. The geochemical interpretation allowed concluding that the lavas have sodic alkaline affinity and were generated by low partial melting rates, from an enriched mantle-derived magma. The geochemical data are compatible with those of magmas generated in an oceanic intraplate (OIB) geotectonic setting.

Keywords: Ocean Island Basalt, Azores Archipelago, São Jorge Island.

\section{INTRODUÇÃO}

Os vulcões de ambiente intraplaca oceânico são úteis para compreender a composição do manto astenosférico da Terra e os processos de geração e evolução de magmas. O magmatismo de ilha oceânica apresenta várias fases de atividade vulcânica e cada uma delas possui composições químicas e isotópicas distintas
(Beier et al., 2006). Assim, a ascensão dos magmas abaixo dos vulcões intraoceânicos requer um estudo detalhado para distinguir magmas primários de magmas contaminados (com o manto litosférico e/ou crosta oceânica) e compreender as diferentes fontes de magmas geradores dessas rochas (Beier et al., 2006). 
As ilhas do Arquipélago dos Açores são consideradas um laboratório natural para estudar os processos mantélicos e magmáticos, considerando que são ilhas oceânicas situadas em um cenário tectônico complexo, nas proximidades da Cordilheira Meso-Atlântica (CMA) (Ribeiro, 2011). Anomalias topográficas, gravimétricas, de espessamento crustal, de velocidades de propagação de ondas sísmicas, térmicas e geoquímicas encontradas na região dos Açores são interpretadas como evidências da existência de uma pluma mantélica sob a região (Gente et al., 2003; Pacheco et al., 2013).

A presença de três placas tectônicas (NorteAmericana, Euro-Asiática e Africana) próximo aos Açores é importante na distribuição do material da pluma no manto superior e influencia no padrão espacial do vulcanismo de fundo oceânico (Georgen, 2011). Essa proximidade resultou em uma interação entre a CMA e o Hotspot dos Açores, e como consequência, gerou uma assinatura geoquímica assimétrica, com diferenças ou desconformidades nos padrões das rochas do arquipélago. O início da interação entre a CMA e o Hotspot dos Açores ocorreu há $85 \mathrm{Ma}$, enquanto o período da construção do Platô dos Açores se iniciou há $20 \mathrm{Ma}$ (Gente et al., 2003).

A evolução do Arquipélago dos Açores não segue o modelo de hotspot convencional, no qual o vulcanismo se desenvolve numa sequência temporal, como foi proposto para o Hotspot do Hawaí. Nos Açores, a ausência de uma sequência temporal entre as ilhas é o resultado da rápida movimentação das placas sobre a pluma e o seu desenvolvimento foi preferencialmente controlado pela tectônica extensional complexa da junção tríplice (JT) (Larrea et al., 2014).

$\mathrm{O}$ presente trabalho visou o tratamento e a interpretação de dados petrográficos e geoquímicos das rochas vulcânicas da Ilha São Jorge com o intuito de identificar e descrever a mineralogia e as texturas dos diferentes sistemas vulcânicos, bem como entender os processos magmáticos e a afinidade geoquímica do magmatismo.

\section{GEOLOGIA REGIONAL}

O Arquipélago dos Açores está localizado no Oceano Atlântico Norte, a 1.600 km de Portugal Continental, na latitude $37^{\circ}-40^{\circ} \mathrm{N}$ e longitude $25^{\circ}-31^{\circ} \mathrm{W}$, com largura de aproximadamente $600 \mathrm{~km}$ (Figura 1). Essa região possui topografia elevada (1,5 km de altitude), com vulcões formados por atividade de um hotspot (Gente et al., 2003).

Os Açores se encontram na convergência de três placas tectônicas (Norte-Americana, EuroAsiática e Africana), que formam uma junção tríplice, com várias estruturas tectônicas nas proximidades, as quais influenciam o vulcanismo e a sismicidade da região. Dentre as estruturas, estão a CMA, o Rifte da Terceira (RT), a Zona de Fratura Norte dos Açores (ZFNA), a Zona de Fratura Faial-Pico (ZFFP), a Zona de Fratura Banco Açor (ZFBA), a Zona de Fratura Banco Princesa Alice (ZFBPA), a Falha da Glória (FG) e a Transformante Leaky de São Jorge (TSJ) (Figura 1).

Geograficamente, as ilhas do Arquipélago dos Açores são distribuídas em três grupos denominados Grupo Oriental (Santa Maria e São Miguel), Grupo Central (Terceira, Graciosa, São Jorge, Faial e Pico) e Grupo Ocidental (Flores e Corvo) (Figura 1). A ilha mais antiga do Arquipélago é Santa Maria, com idade de 8,12 \pm 0,85 Ma (K/Ar), enquanto a Ilha São Miguel tem
4,01 $\pm 0,50 \mathrm{Ma}(\mathrm{K} / \mathrm{Ar})$ (Abdel-Monem et al., 1975). A Ilha da Terceira possui 3,52 Ma (Ferreira \& Azevedo, 1995). As idades existentes para a Ilha da Graciosa são de $2,5 \mathrm{Ma}(\mathrm{Rb} / \mathrm{Sr})$ (White et al., 1976) e de um intervalo entre 1,05 $\pm 0,028 \mathrm{Ma}$ e $3,9 \pm 1,4 \mathrm{ka}\left({ }^{40} \mathrm{Ar} /{ }^{39} \mathrm{Ar}\right.$ ) (Larrea et al., 2014).

A idade geocronológica mais antiga relatada para a Ilha São Jorge é de 1,309 $\pm 0,0035 \mathrm{Ma}$ $\left({ }^{40} \mathrm{Ar} /{ }^{39} \mathrm{Ar}\right)$ (Ribeiro, 2011). As idades conhecidas para as ilhas do Faial e Pico são, respectivamente, $0,85 \pm 0,012 \mathrm{Ma}(\mathrm{K} / \mathrm{Ar})$ (Hildenbrand et al., 2012) e 0,27 Ma (Demand et al., 1982). As ilhas localizadas a oeste da CMA, no Grupo Ocidental, apresentam idades de 2,16 $\pm 0,16 \mathrm{Ma}$ (Ilha das Flores, Azevedo et al., 2006) e 0,7 Ma (Ilha do Corvo, Azevedo et al, 2003).

As rochas mais comuns nas ilhas açorianas são basaltos alcalinos e hawaítos (Beier et al., 2010), podendo ocorrer picritos, mugearitos e traquitos (França et al., 2005).

Do ponto de vista geoquímico, as lavas das ilhas açorianas são heterogêneas em termos de composições isotópicas radiogênicas, mas apresentam homogeneidade em relação aos valores dos elementos maiores e a maioria dos elementos traços incompatíveis (Beier et al., 2012). Assim, o padrão na composição da fonte do magma é assimétrico para as ilhas do 
arquipélago (Gente et al., 2003; Beier et al., 2010). Os Açores têm composições de reservatórios mantélicos do tipo HIMU (Alto $\left.{ }^{238} \mathrm{U} /{ }^{204} \mathrm{~Pb}\right), \quad \mathrm{DMM} \quad(\mathrm{MORB}$ de Manto Empobrecido) e EM (Manto Enriquecido) (França et al., 2005).

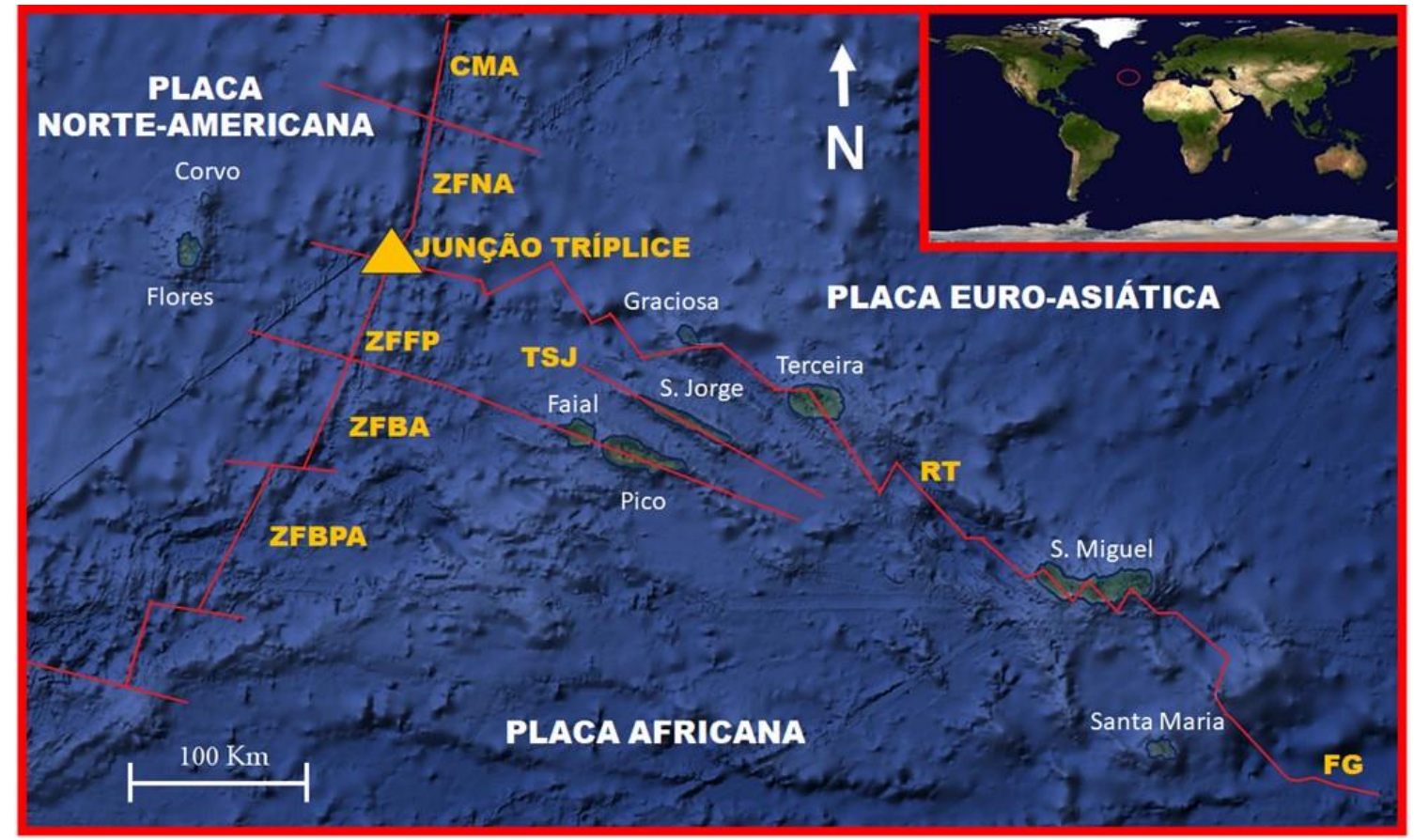

Figura 1 - Principais estruturas tectônicas nas proximidades da junção tríplice (Fonte: Nunes, 1999). Sobreposição em imagem de satélite (Fonte: Google Earth, 2018). Cordilheira Meso-Atlântica (CMA); Rifte da Terceira (RT); Zona de Fratura Norte dos Açores (ZFNA); Zona de Fratura Faial-Pico (ZFFP); Zona de Fratura Banco Açor (ZFBA); Zona de Fratura Banco Princesa Alice (ZFBPA); Falha da Glória (FG); Transformante Leaky de São Jorge (TSJ).

\section{GEOLOGIA LOCAL}

A Ilha São Jorge localiza-se no Atlântico Norte, entre $38^{\circ} 33^{\prime}$ e $38^{\circ} 45^{\prime} \mathrm{N}$ de latitude e $27^{\circ}$ $44^{\prime}$ e $28^{\circ} 20^{\prime} \mathrm{W}$ de longitude. Essa ilha apresenta forma alongada e área de $245,8 \mathrm{~km}^{2}$, com $55 \mathrm{~km}$ de comprimento e $7 \mathrm{~km}$ de largura. $\mathrm{O}$ estilo eruptivo do vulcanismo é fissural, com orientação preferencial WNW-ESE, o que revela a importância do controle tectônico durante a atividade vulcânica (Ribeiro, 2011).

A vulcanoestratigrafia da ilha é caracterizada por três complexos vulcânicos: Topo, Rosais e Manadas (Forjaz \& Fernandes, 1970, 1975; Mendes et al., 2013) (Figura 2).

O Complexo Vulcânico Topo (CVT) foi o primeiro sistema vulcânico formado e aflora na parte leste da ilha. A unidade é composta por derrames vulcânicos espessos, devido à predominância de fluxos de lava do tipo "aa" (França et al., 2005) em relação ao material piroclástico.

As sequências do CVT são cortadas por diques orientados pelo sistema tectônico regional (Ribeiro, 2011). As rochas presentes no CVT são basanitos, tefritos, basaltos e hawaítos (Larrea et al., 2018). Um estudo recente de Ribeiro (2011) propôs que a Fajã de São João, com idade
${ }^{40} \mathrm{Ar} /{ }^{39} \mathrm{Ar}$ de $1309,8 \pm 3,5 \mathrm{ka} \mathrm{e} 1284,0 \pm 4,8 \mathrm{ka}$, é a parte mais antiga da ilha (Figura 2) e apresenta uma sequência de derrames com mais de $400 \mathrm{~m}$ de espessura. A posição estratigráfica das lavas mais jovens desse complexo (543 ka) fornece um limite importante para o fim da atividade vulcânica do CVT (Ribeiro, 2011).

O Complexo Vulcânico Rosais (CVR) aflora na porção oeste da ilha e possui contato estratigráfico não visível com o CVT, pois foi coberto pelas lavas recentes do Complexo Vulcânico Manadas (Pacheco et al., 2013). No CVR ocorrem basanitos, basaltos, hawaítos e traquibasaltos potássicos (Ribeiro, 2011), sendo que as lavas são do tipo "aa" (França et al., 2005). Nessa unidade, as idades ${ }^{40} \mathrm{Ar} /{ }^{39} \mathrm{Ar}$ variam entre $270,1 \pm 2,5 \mathrm{ka}$ e $116,6 \pm 2,0 \mathrm{ka}$ (Ribeiro, 2011).

O Complexo Vulcânico Manadas (CVM) está inserido na parte central da Ilha São Jorge e representa a unidade geológica mais jovem. Esse sistema vulcânico é composto por numerosos cones estrombolianos recentes (Larrea et al., 2018) e dois surtesianos: Morro do Lemos e Morro Velho (França et al., 2005). O CVM é considerado ativo e as duas últimas erupções históricas ocorreram em 1.580, na Fajã da 
Queimada, e no ano 1.808, em Urzelina (França et al., 2005; Larrea et al., 2018), além de um provável evento submarino em 1.964 , que foi identificado pelo cheiro sulfuroso na região (Forjaz \& Fernandez, 1975; Ribeiro, 2011; Pacheco et al., 2013).

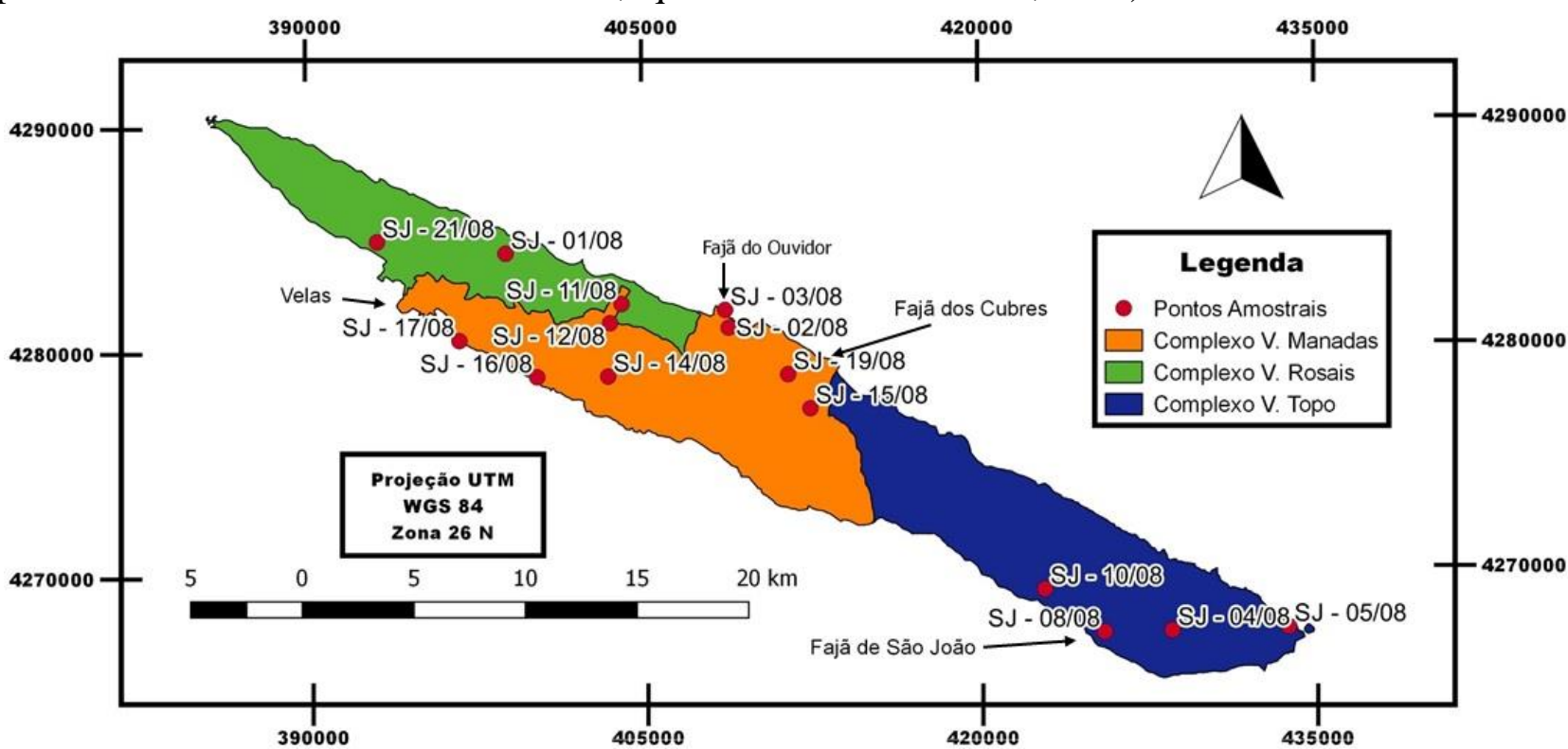

Figura 2 - Mapa vulcanoestratigráfico e a localização das amostras que foram utilizadas na elaboração desse trabalho. As unidades geológicas foram definidas por Forjaz \& Fernandes (1970 e 1975).

Basanitos, tefritos, basaltos, hawaítos e mugearitos são as litologias que ocorrem no CVM (Larrea et al., 2018). Essa unidade apresenta uma exposição excelente de rochas básicas e uma expressiva heterogeneidade morfológica dos derrames, o que favorece o estudo detalhado em escala de afloramento (Rossetti et al., 2015). Os dados geocronológicos indicam a idade ${ }^{40} \mathrm{Ar} /{ }^{39} \mathrm{Ar}$ do CVM entre 2,9 \pm 10,3 ka, e 0,5 $\pm 6,9 \mathrm{ka}$ (Ribeiro, 2011).

França (2009) determinou a tipicidade vulcânica da Ilha São Jorge, como sugestiva de vulcanismo efusivo de baixa a média explosividade, do tipo hawaiano e principalmente estromboliano, com base nas descrições das estruturas e produtos vulcânicos das erupções históricas das ilhas açorianas. Conforme Ribeiro (2011), o estilo hidromagmático ocorre no CVM.

Os dados de campo mostraram que os afloramentos da ilha apresentam fluxos de lava dos tipos "aa" e "pahoehoe" (Figura 3), sobrepondo-se aos depósitos piroclásticos. As sequências vulcânicas são intrudidas, frequentemente, por diques. Cones de escória com cristais de augita alterados foram observados no CVT.

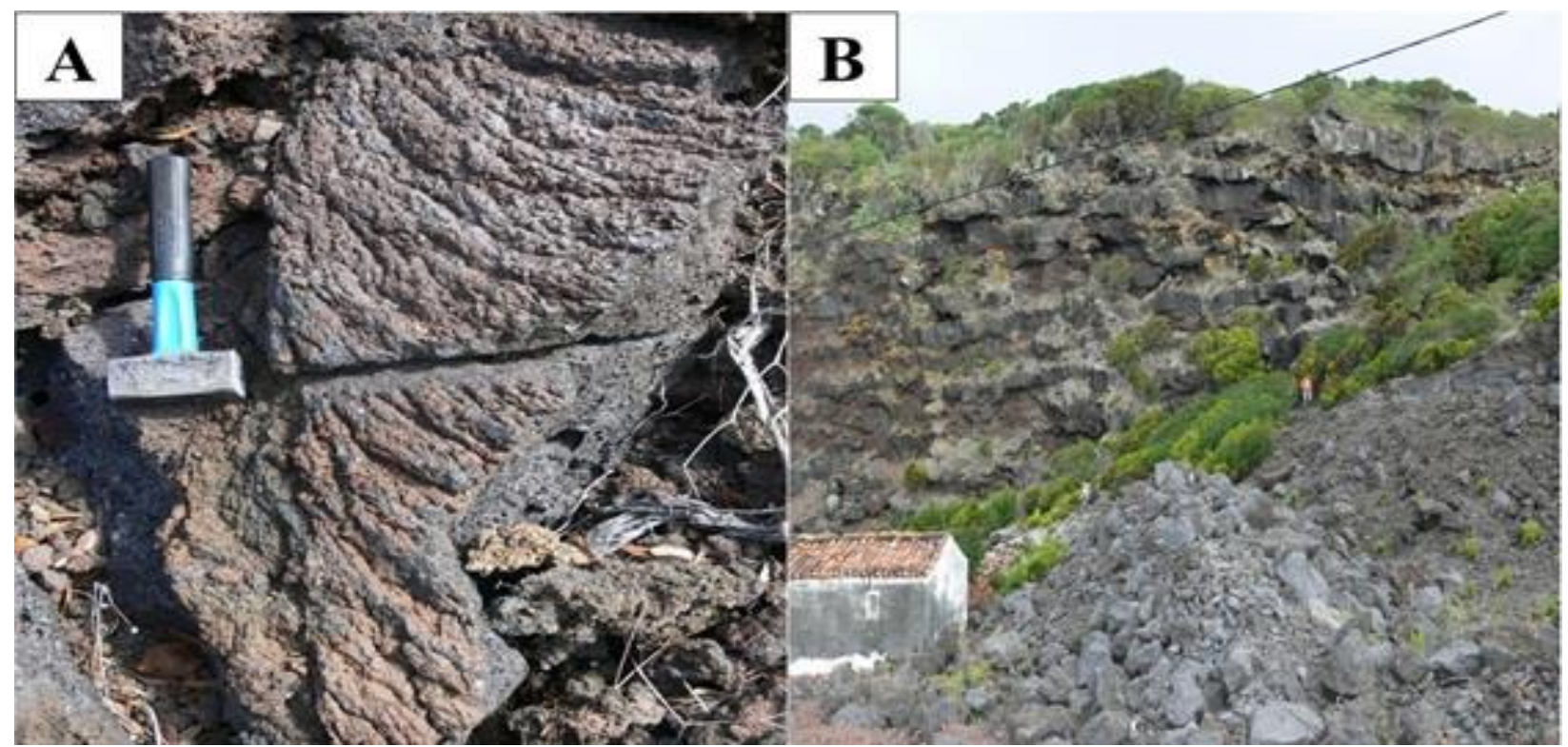

Figura 3 - Afloramentos da Ilha São Jorge. A) Fluxo de lava do tipo "pahoehoe" B) Fluxo de lava do tipo "aa". 
As rochas vulcânicas da Ilha São Jorge relacionadas a este trabalho são representadas por basanitos, basaltos alcalinos e hawaítos pertencentes aos complexos vulcânicos Topo, Rosais e Manadas.
Os pontos dos afloramentos estudados foram plotados no mapa geológico (Figura 2). As amostras, as coordenadas dos pontos, as litologias e as unidades vulcanoestratigráficas estão inseridas na tabela 1 .

Tabela 1 - Identificação das amostras, localização, litologia e unidades vulcanoestratigráficas.

\begin{tabular}{cccc} 
Amostra & Coordenadas UTM & Litologia & Unidade \\
\hline SJ-01/08 & $398845 / 4284259$ & basanito & Complexo Vulc. Rosais \\
\hline SJ-02/08 & $408777 / 4280854$ & hawaito & Comp. Vulc. Manadas \\
SJ-03/08 & $408627 / 4281644$ & basalto alcalino & Comp. Vulc. Manadas \\
\hline SJ-04/08 & $428515 / 4267200$ & hawaito & Comp. Vulc. Topo \\
SJ-05/08 & $433729 / 4267329$ & hawaito & Comp. Vulc. Topo \\
SJ-08/08 & $425486 / 4267151$ & hawaito & Comp. Vulc. Topo \\
SJ-10/08 & $422818 / 4269082$ & hawaito & Comp. Vulc. Topo \\
SJ-11/08 & $404003 / 4281960$ & hawaito & Comp. Vulc. Manadas \\
SJ-12/08 & $403477 / 4281111$ & basalto alcalino & Comp. Vulc. Manadas \\
SJ-14/08 & $403368 / 4278740$ & hawaito & Comp. Vulc. Manadas \\
SJ-15/08 & $412400 / 4277227$ & hawaito & Comp. Vulc. Manadas \\
SJ-16/08 & $400195 / 4278745$ & hawaito & Comp. Vulc. Manadas \\
SJ-17/08 & $396732 / 4280401$ & basanito & Comp. Vulc. Manadas \\
SJ-19/08 & $411417 / 4278754$ & basalto alcalino & Comp. Vulc. Manadas \\
SJ-21/08 & $393105 / 4284838$ & basalto alcalino & Complexo Vulc. Rosais
\end{tabular}

\section{MATERIAIS E MÉTODOS}

A partir das 23 amostras coletadas em trabalho de campo, 15 lâminas delgadas foram confeccionadas no Laboratório de Preparação de Lâminas Delgadas do Departamento de Geociências da Universidade de Aveiro (Portugal).

A descrição foi realizada com o auxílio do microscópio petrográfico Olympus BX41, do Laboratório de Microscopia e Lupas do Departamento de Geologia da Universidade Federal de Sergipe (UFS). A estimativa modal foi realizada pelo método da contagem de pontos, através de uma varredura em toda a lâmina, até atingir em média 800 pontos.

Para os estudos de geoquímica de rocha total, as amostras foram britadas e moídas ( $<200$ mesh) no Activation Laboratories Ltd. (ACTLABS Ontário, Canadá - amostras SJ-02/08, SJ-03/08, SJ-05/08，SJ-10/08，SJ-14/08，SJ-15/08，SJ16/08 e SJ-17/08) e Acme Analytical Laboratories Ltd. (ACME - Vancouver, Canadá
- amostras SJ-01/08, SJ-04/08, SJ-08/08, SJ11/08, SJ-12/08, SJ-19/08, SJ-21/08). A análise de elementos maiores foi realizada por meio de plasma acoplado indutivamente (ICP) no ACTLABS e no ACME. Os dados de elementostraço e terras raras foram obtidos pela técnica de espectrometria de massa (ICP-MS), em ambos os laboratórios. No ACTLABS, os limites de detecção apresentam valores de $0,01 \%$ para todos os óxidos, com exceção de $\mathrm{MnO}$ e $\mathrm{TiO}_{2}$, com $0,001 \%$. Para os elementos-traço e terras raras, os limites de detecção são geralmente inferiores a 5 ppm, à exceção de $\mathrm{Cr}$ e Ni, com 20 ppm. No ACME, os óxidos apresentam limites de detecção de $0,01 \%$, exceto o $\mathrm{Fe}_{2} \mathrm{O}_{3}{ }^{\mathrm{t}}(0,04 \%)$. Os elementos-traço e os terras raras possuem limites de detecção abaixo de 5 ppm, com exceção do Ni (20 ppm) e do V (8 ppm). Por fim, os dados das análises químicas das 15 amostras foram tratados através de diagramas confeccionados no Software Microsoft Excel 2016.

\section{RESULTADOS}

\section{Petrografia}

As rochas vulcânicas estudadas da Ilha São Jorge afloram como fluxos de lava e apresentam textura porfirítica, microporfirítica, glomeroporfirítica, intergranular, pilotaxítica, traquítica e intersertal. A mineralogia é composta por fenocristais de olivina, augita, plagioclásio e minerais opacos, imersos em uma matriz com a mesma composição mineralógica dos fenocristais.

De acordo com o diagrama Total Álcalis versus Sílica (TAS) (Middlemost, 1994), as rochas vulcânicas estudadas foram classificadas como basanito, basalto alcalino e hawaíto. A 
kaersutita foi identificada em algumas amostras de basalto alcalino e hawaíto. Os dados da contagem modal obtidos na petrografia estão disponíveis na tabela 2.

Tabela 2 - Dados da contagem modal baseada na porcentagem (\%) de fenocristal e matriz das rochas vulcânicas estudadas na Ilha São Jorge (Abreviaturas: Siivola \& Schmid, 2007).

\begin{tabular}{lccccccc}
\hline Amostra & Litologia & OI & Aug & PI & Op & Krs & Matriz \\
SJ-01/08 & basanito & 12,2 & 23,2 & 5,4 & 0 & 0 & 59,2 \\
\hline SJ-17/08 & basanito & 4,9 & 4,6 & 8,3 & 0,3 & 0 & 81,9 \\
SJ-03/08 & basalto alcalino & 1,8 & 0,2 & 7,7 & 1,8 & 0,3 & 88,2 \\
\hline SJ-12/08 & basalto alcalino & 0,6 & 1,1 & 17,5 & 0,4 & 1,2 & 79,2 \\
SJ-19/08 & basalto alcalino & 1,2 & 0 & 13 & 0,8 & 0 & 85 \\
SJ-21/08 & basalto alcalino & 3,3 & 3,5 & 6,3 & 0 & 0 & 86,9 \\
SJ-02/08 & hawaíto & 1,4 & 0,7 & 1,9 & 0,2 & 0 & 95,8 \\
SJ-04/08 & hawaíto & 0 & 0 & 0,3 & 0 & 0 & 99,7 \\
SJ-05/08 & hawaíto & 1,9 & 0,3 & 0 & 0 & 0,1 & 97,7 \\
SJ-08/08 & hawaíto & 0 & 0 & 1 & 0 & 0 & 99 \\
SJ-10/08 & hawaíto & 4,7 & 0,9 & 0,1 & 0 & 0 & 94,3 \\
SJ-11/08 & hawaíto & 0,7 & 1,3 & 10,8 & 1,6 & 1,1 & 84,5 \\
SJ-14/08 & hawaíto & 0,2 & 0 & 0,8 & 0 & 0 & 99 \\
SJ-15/08 & hawaíto & 5,6 & 3,2 & 22,2 & 0 & 0 & 69 \\
SJ-16/08 & hawaíto & 1 & 2,3 & 13,2 & 1,1 & 0 & 82,4
\end{tabular}

\section{Basanitos}

Os basanitos apresentam textura porfirítica (Figura 4A) com matriz pilotaxítica e intersertal. Os fenocristais são de olivina $(4,9 \%-12,2 \%)$, augita $(4,6 \%$ - 23,2\%), plagioclásio $(5,4 \%$ $8,3 \%$ ) e minerais opacos (Ausente - 0,3\%). Os minerais da matriz $(59,2 \%-81,9 \%)$ têm de 0,01 a $0,5 \mathrm{~mm}$, sendo dos mesmos tipos que os fenocristais. A matriz também contém vidro vulcânico e vesículas arredondadas.

A olivina ocorre predominantemente como fenocristal ( 0,7 a 4,2 mm), além de estar presente na matriz. Este mineral varia de euédrico a predominantemente subédrico, com contatos retos a curvos com a matriz. Alguns cristais de olivina apresentam inclusões de augita (bordas) e minerais opacos (centro e bordas). Raros cristais apresentam feições de reabsorção.

A augita ocorre principalmente como fenocristal $(0,7$ a $8,6 \mathrm{~mm})$ e varia de anédrica a euédrica, predominando os contornos subédricos. A cor do mineral é marrom clara e os contatos são predominantemente retos e ocasionalmente curvos com a matriz e o plagioclásio. Por vezes, possui inclusões de minerais opacos e olivina (centro), plagioclásio (bordas) e vidro vulcânico (centro e bordas). Alguns cristais apresentam maclas, zonação (Figura 4A) ou feições de reabsorção.

Os fenocristais de plagioclásio $(0,7$ a $6 \mathrm{~mm})$ são subédricos a euédricos, com predominância dos subédricos. Os cristais possuem contatos retos a curvos com a matriz e a augita, predominando os retos. A presença de fraturas e feições de reabsorção são comuns. Alguns cristais apresentam inclusões de olivina, augita, minerais opacos e vidro vulcânico (centro e bordas). Raramente, observam-se cristais zonados. Na matriz, esses cristais são ripiformes.

Os fenocristais de minerais opacos $(0,7$ a 1,2 $\mathrm{mm}$ ) são subédricos, com contatos retos a curvos com a matriz, predominando os curvos.

\section{Basaltos Alcalinos}

Os basaltos alcalinos apresentam textura porfirítica, com matriz pilotaxítica, intergranular e intersertal. Uma amostra apresenta textura glomeroporfirítica (plagioclásio - Figura 4B). Essas rochas são compostas por fenocristais de olivina $(0,6 \%-3,3 \%)$, augita (ausente $-3,5 \%$ ), plagioclásio $(6,3 \%$ - 17,5\%), minerais opacos (ausente - 1,8\%) e kaersutita (ausente - 1,2\%). A matriz $(79,2 \%-88,2 \%)$ possui granulometria de 0,01 a $0,5 \mathrm{~mm}$ e é constituída por todos os minerais presentes como fenocristais, além de vidro vulcânico e vesículas alongadas ou arredondadas.

A olivina ocorre predominantemente como fenocristal $(0,7$ a $3,5 \mathrm{~mm})$ e apresenta contornos anédricos a euédricos, predominando os subédricos, com contatos retos a curvos, com a olivina, a augita, o plagioclásio e a matriz, predominando os retos. Alguns cristais possuem inclusões de augita (centro), minerais opacos e vidro vulcânico (bordas). Ocasionalmente, os cristais possuem feições de reabsorção, macla, fraturas e oxidação.

A augita ocorre principalmente como 
fenocristal (0,6 a 6,5 mm), com contornos euédricos a predominantemente anédricos. A cor do mineral é marrom clara. Os contatos são retos a curvos, com a olivina, o plagioclásio, a kaersutita e a matriz, com predominância dos curvos. Por vezes, possui inclusões de minerais opacos e vidro vulcânico (centro e bordas), plagioclásio e olivina (centro) (Figura 4C). Alguns cristais apresentam macla ou zonação, com feições de reabsorção (Figura 4C), bem como ocorrem raros cristais alteram para epidoto.

Os fenocristais de plagioclásio $(0,6$ a 8,6 mm) são anédricos a euédricos, com predominância dos subédricos. Os contatos são retos a curvos, com a olivina, a augita, o plagioclásio e a matriz, predominando os retos. Alguns cristais apresentam inclusões de olivina, augita, minerais opacos e vidro vulcânico (centro e bordas -Figura 4B). Raramente, observam-se cristais zonados, maclados, com textura sieve fina (Figura 4D) ou sieve grossa (Figura 4E), bem como embainhamento nas bordas. Alguns cristais incluem vidro vulcânico alterado (borda). $\mathrm{Na}$ matriz, esses cristais são ripiformes.

Os fenocristais de minerais opacos $(0,7$ a 2,6 $\mathrm{mm})$ são anédricos a subédricos, com predominância dos subédricos, e têm contatos retos a curvos com a matriz, predominando os curvos.

A kaersutita ocorre predominantemente como fenocristal $(0,7$ a $3,3 \mathrm{~mm})$, apresenta cor marrom escura e contorno anédrico. Os contatos são curvos com a augita e a matriz. Alguns cristais incluem plagioclásio (centro), além de olivina, augita e vidro vulcânico (centro e bordas). Todos os cristais apresentam borda de reação de minerais opacos. A presença da kaersutita com borda de reação no basalto alcalino sugere que esse mineral seria um xenocristal, corroborando a interpretação de Ribeiro (2011).

\section{Hawaítos}

Os hawaítos apresentam textura porfirítica comum, com matriz intersertal e intergranular, por vezes traquítica (Figura 4F) ou pilotaxítica. Ocasionalmente possuem textura glomeroporfirítica (olivina, augita, plagioclásio e minerais opacos).

As rochas são compostas por fenocristais de olivina (ausente $-5,6 \%$ ), augita (ausente $-3,2 \%$ ), plagioclásio (ausente - 22,2\%), minerais opacos (ausente - 1,6\%) e kaersutita (ausente - 1,1\%). Os fenocristais estão inseridos em uma matriz $(69 \%$ - 99,7\%) com granulometria de 0,01 a $0,5 \mathrm{~mm}$, constituída por todos os minerais presentes como fenocristais, além de vidro vulcânico. Em algumas rochas, observa-se a presença de vesículas arredondadas ou alongadas.

A olivina ocorre predominantemente como fenocristal $(0,7$ a $3,7 \mathrm{~mm})$ e apresenta contornos anédricos a euédricos, predominando os subédricos. Os contatos são retos a curvos com a matriz, predominando os retos. Alguns cristais incluem olivina (centro), além de minerais opacos e vidro vulcânico (centro e bordas). Por vezes, observam-se cristais maclados e com porções oxidadas (Figura 4G), além de fraturas preenchidas por bowlingita (Figura 4I) e feições de reabsorção. Alguns cristais apresentam embainhamento nas bordas (Figura 4G).

A augita como fenocristal $(0,7$ e $3,5 \mathrm{~mm})$ é anédrica a euédrica, predominando a subédrica. A cor do mineral é marrom clara. Os contatos são retos a curvos com minerais opacos e matriz, com predominância dos curvos. Por vezes, possui inclusões de olivina, plagioclásio, minerais opacos e vidro vulcânico (centro e bordas). Ocasionalmente ocorrem feições de reabsorção, maclas e zonação. Raros cristais alteram para epidoto (Figura 4H).

Os fenocristais de plagioclásio ( 0,7 a 5,6 mm) são anédricos a euédricos, com predominância dos subédricos. Os contatos são retos a curvos, com minerais opacos e matriz, predominando os retos. Alguns cristais apresentam inclusões de olivina, plagioclásio, augita, minerais opacos e vidro vulcânico (centro e bordas). Raramente, ocorrem cristais zonados, com textura sieve fina ou com embainhamento nas bordas. Na matriz, esses cristais são ripiformes.

Os fenocristais de minerais opacos $(0,6$ a 2,8 $\mathrm{mm})$ são anédricos a euédricos, com predominância dos subédricos, e têm contatos retos a curvos com augita, plagioclásio e matriz, predominando os curvos.

A kaersutita ocorre predominantemente como fenocristal ( 0,7 a 5,8 $\mathrm{mm})$, apresenta cor marrom escura e varia de anédrica a subédrica, predominando a anédrica. Os contatos são retos a curvos com a matriz, predominando os curvos. Ocorre com borda de reação de minerais opacos (Figura 4J), sugerindo ser um xenocristal.

\section{Geoquímica}

Os dados químicos de rocha total de 15 amostras de rochas efusivas dos CVT, CVR e CVM da Ilha São Jorge (Tabelas 3 e 4) foram plotados em diagramas geoquímicos. 

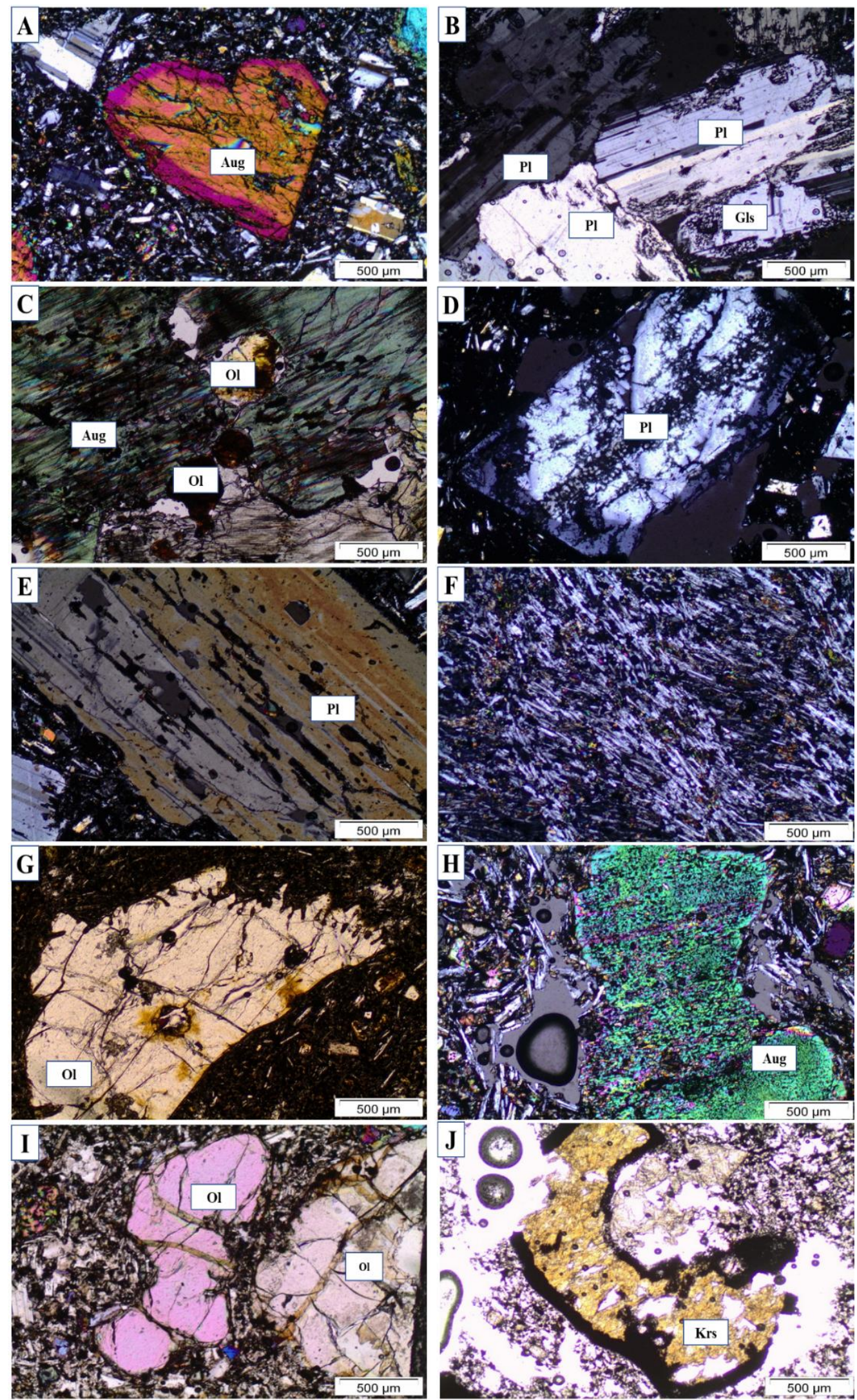

Figura 4 - Aspectos microscópicos das rochas da Ilha São Jorge em luz polarizada (LP) e em luz natural (LN). A) Textura porfirítica, exibindo augita zonada em basanito, LP (SJ-01/08); B) Textura glomeroporfirítica constituída por plagioclásio com inclusão de vidro vulcânico em basalto alcalino, LP (SJ- 12/08); C) Augita com feição de reabsorção e inclusão de olivina com óxido de ferro em basalto alcalino, LP (SJ- 21/08); D) Plagioclásio zonado, com textura sieve fina em basalto alcalino, LP (SJ-03/08); E) Plagioclásio com textura sieve grossa em basalto alcalino, LP (SJ-19/08). F) Matriz com textura traquítica, intersertal e intergranular em hawaítos, LP (SJ-04/08); G) Olivina com embainhamento nas bordas e oxidação em hawaítos, LN (SJ-05/08); H) Augita alterando para epidoto, no hawaíto, LP (SJ-10/08); I) Olivina com porções oxidadas e presença de bowlingita nas fraturas em hawaíto, LP (SJ-15/08) J) Kaersutita com borda de reação de minerais opacos em hawaíto, LN (SJ-11/08). (Abreviaturas: Chace, 1956; Siivola \& Schmid, 2007). 
Tabela 3 - Análises químicas de rocha total dos basanitos e basaltos alcalinos da Ilha São Jorge (elementos maiores e menores em \% peso; traços e terras raras em ppm). CVM = Complexo Vulcânico Manadas; CVR = Comp. Vul. Rosais; CVT = Comp. Vul. Topo; P.F. = Perda ao Fogo; n.d. = não detectado.

\begin{tabular}{|c|c|c|c|c|c|c|}
\hline Unidade & CVR & CVM & CVM & CVM & CVM & CVR \\
\hline $\begin{array}{c}\text { Tipo de } \\
\text { rocha }\end{array}$ & \multicolumn{2}{|c|}{ Basanito } & \multicolumn{4}{|c|}{ Basalto Alcalino } \\
\hline Amostra & SJ-01/08 & SJ-17/08 & SJ-03/08 & SJ-12/08 & SJ-19/08 & SJ-21/08 \\
\hline $\mathrm{SiO}_{2}(\%)$ & 44,68 & 43,90 & 45,42 & 45,84 & 45,40 & 46,09 \\
\hline $\mathrm{TiO}_{2}$ & 2,88 & 4,22 & 3,67 & 3,47 & 3,89 & 3,48 \\
\hline $\mathrm{Al}_{2} \mathrm{O}_{3}$ & 13,42 & 16,35 & 16,38 & 17,18 & 17,04 & 16,89 \\
\hline $\mathrm{Fe}_{2} \mathrm{O}_{3}{ }^{\mathrm{T}}$ & 12,31 & 13,10 & 12,27 & 12,75 & 12,52 & 12,41 \\
\hline $\mathrm{MnO}$ & 0,16 & 0,17 & 0,18 & 0,19 & 0,17 & 0,19 \\
\hline $\mathrm{MgO}$ & 11,74 & 8,24 & 5,45 & 5,20 & 5,73 & 5,58 \\
\hline $\mathrm{CaO}$ & 11,00 & 10,44 & 9,53 & 8,68 & 9,48 & 8,77 \\
\hline $\mathrm{Na}_{2} \mathrm{O}$ & 2,28 & 2,97 & 3,37 & 3,65 & 3,56 & 3,27 \\
\hline $\mathrm{K}_{2} \mathrm{O}$ & 0,76 & 1,07 & 1,23 & 1,37 & 1,34 & 1,39 \\
\hline $\mathrm{P}_{2} \mathrm{O}_{3}$ & 0,40 & 0,55 & 0,72 & 0,91 & 0,68 & 0,75 \\
\hline P.F. & 0,10 & 0,48 & 0,08 & 0,40 & 0,20 & 0,80 \\
\hline Total & 99,53 & 100,53 & 98,14 & 99,64 & 99,61 & 99,62 \\
\hline $\mathrm{Rb}(\mathrm{ppm})$ & 14,40 & 20,00 & 27,00 & 21,10 & 25,80 & 25,30 \\
\hline $\mathrm{Ba}$ & 216,00 & 270,00 & 549,00 & 374,00 & 332,00 & 394,00 \\
\hline $\mathrm{Sr}$ & 605,90 & 709,00 & 824,00 & 884,60 & 838,60 & 834,10 \\
\hline $\mathrm{Ni}$ & 192,00 & 110,00 & 70,00 & n.d. & 44,00 & 46,00 \\
\hline $\mathrm{Cr}$ & - & 150,00 & 50,00 & - & - & - \\
\hline $\mathrm{Co}$ & 57,80 & 51,00 & 36,00 & 31,90 & 36,10 & 35,50 \\
\hline $\mathrm{Nb}$ & 31,60 & 46,00 & 61,00 & 55,40 & 50,90 & 60,40 \\
\hline $\mathrm{Zr}$ & 195,70 & 227,00 & 296,00 & 300,30 & 281,40 & 329,10 \\
\hline$Y$ & 23,70 & 25,00 & 30,00 & 31,80 & 28,80 & 32,50 \\
\hline $\mathrm{Hf}$ & 5,10 & 5,40 & 6,20 & 7,00 & 7,10 & 8,10 \\
\hline U & 0,80 & 0,90 & 1,50 & 1,30 & 1,30 & 1,60 \\
\hline Th & 2,50 & 2,80 & 6,30 & 3,70 & 3,90 & 5,30 \\
\hline $\mathrm{Pb}$ & 0,80 & n.d. & 12,00 & 1,40 & 1,10 & 1,40 \\
\hline $\mathrm{Ga}$ & 17,40 & 22,00 & 26,00 & 23,70 & 22,10 & 22,20 \\
\hline Sc & 29,00 & 24,00 & 17,00 & 15,00 & 19,00 & 18,00 \\
\hline V & 267,00 & 353,00 & 277,00 & 206,00 & 262,00 & 230,00 \\
\hline Cs & n.d. & n.d. & n.d. & 0,20 & 0,20 & 0,10 \\
\hline Ta & 2,50 & 3,50 & 4,10 & 3,90 & 3,80 & 4,30 \\
\hline Sn & 2,00 & 2,00 & 4,00 & 2,00 & 3,00 & 3,00 \\
\hline La & 22,40 & 31,10 & 43,40 & 37,50 & 32,80 & 38,40 \\
\hline $\mathrm{Ce}$ & 48,00 & 68,90 & 91,70 & 78,90 & 68,80 & 79,20 \\
\hline $\mathrm{Pr}$ & 6,50 & 8,77 & 11,60 & 10,74 & 9,28 & 10,63 \\
\hline $\mathrm{Nd}$ & 27,90 & 36,70 & 47,70 & 46,10 & 39,60 & 44,90 \\
\hline $\mathrm{Sm}$ & 6,15 & 8,00 & 10,00 & 9,13 & 8,25 & 9,14 \\
\hline Eu & 2,15 & 2,52 & 3,15 & 3,25 & 2,88 & 3,10 \\
\hline $\mathrm{Gd}$ & 5,98 & 7,20 & 9,10 & 8,45 & 7,39 & 8,14 \\
\hline $\mathrm{Tb}$ & 0,94 & 1,10 & 1,30 & 1,29 & 1,17 & 1,27 \\
\hline Dy & 4,64 & 5,50 & 6,70 & 6,05 & 5,65 & 6,16 \\
\hline Ho & 0,84 & 1,00 & 1,20 & 1,14 & 1,03 & 1,12 \\
\hline $\mathrm{Er}$ & 2,22 & 2,40 & 3,10 & 2,89 & 2,64 & 3,06 \\
\hline $\mathrm{Tm}$ & 0,32 & 0,35 & 0,43 & 0,43 & 0,39 & 0,43 \\
\hline $\mathrm{Yb}$ & 1,79 & 2,00 & 2,60 & 2,41 & 2,21 & 2,46 \\
\hline Lu & 0,24 & 0,31 & 0,39 & 0,34 & 0,30 & 0,35 \\
\hline
\end{tabular}


Tabela 4 - Análises químicas de rocha total dos hawaítos da Ilha São Jorge (elementos maiores e menores em \% peso; traços e terras raras em ppm). CVM = Complexo Vulcânico Manadas; CVR = Comp. Vul. Rosais; CVT = Comp. Vul.

Topo; P.F. = Perda ao Fogo; n.d. = não detectado.

\begin{tabular}{|c|c|c|c|c|c|c|c|c|c|}
\hline Unidade & CVM & CVT & CVT & CVT & CVT & CVM & CVM & CVM & CVM \\
\hline $\begin{array}{c}\text { Tipo de } \\
\text { rocha }\end{array}$ & \multicolumn{9}{|c|}{ Hawaíto } \\
\hline Amostra & SJ-02/08 & SJ-04/08 & SJ-05/08 & SJ-08/08 & SJ-10/08 & SJ-11/08 & SJ-14/08 & SJ-15/08 & SJ-16/08 \\
\hline $\mathrm{SiO}_{2}(\%)$ & 48,36 & 47,38 & 46,18 & 48,19 & 47,45 & 45,96 & 46,17 & 46,94 & 47,03 \\
\hline $\mathrm{TiO}_{2}$ & 3,44 & 3,48 & 3,33 & 3,45 & 3,56 & 3,52 & 3,39 & 3,33 & 3,46 \\
\hline $\mathrm{Al}_{2} \mathrm{O}_{3}$ & 16,55 & 16,61 & 14,88 & 15,85 & 16,20 & 16,89 & 17,11 & 17,95 & 18,37 \\
\hline $\mathrm{Fe}_{2} \mathrm{O}_{3}{ }^{\mathrm{T}}$ & 11,69 & 12,68 & 11,92 & 12,49 & 13,13 & 12,87 & 11,29 & 11,47 & 11,35 \\
\hline $\mathrm{MnO}$ & 0,18 & 0,19 & 0,19 & 0,19 & 0,20 & 0,19 & 0,17 & 0,17 & 0,17 \\
\hline $\mathrm{MgO}$ & 5,32 & 4,78 & 8,02 & 4,19 & 4,58 & 5,26 & 5,23 & 5,39 & 5,04 \\
\hline $\mathrm{CaO}$ & 8,41 & 8,29 & 9,67 & 8,44 & 8,04 & 8,65 & 9,03 & 9,22 & 9,81 \\
\hline $\mathrm{Na}_{2} \mathrm{O}$ & 3,99 & 4,31 & 3,70 & 4,04 & 4,59 & 3,77 & 3,93 & 4,02 & 3,92 \\
\hline $\mathrm{K}_{2} \mathrm{O}$ & 1,80 & 1,34 & 1,43 & 1,75 & 1,41 & 1,42 & 1,45 & 1,45 & 1,42 \\
\hline $\mathrm{P}_{2} \mathrm{O}_{3}$ & 0,82 & 0,70 & 0,63 & 0,78 & 0,68 & 0,90 & 0,85 & 0,82 & 0,83 \\
\hline P.F. & 0,31 & 0,10 & 0,23 & 0,30 & 0,01 & 0,20 & 0,23 & 0,17 & 0,47 \\
\hline Total & 100,25 & 99,66 & 100,18 & 99,67 & 99,83 & 99,63 & 98,39 & 100,59 & 100,92 \\
\hline $\mathrm{Rb}(\mathrm{ppm})$ & 33,00 & 28,50 & 28,00 & 37,80 & 27,00 & 27,10 & 29,00 & 28,00 & 27,00 \\
\hline Ba & 454,00 & 382,00 & 344,00 & 431,00 & 395,00 & 387,00 & 364,00 & 371,00 & 359,00 \\
\hline Sr & 835,00 & 815,90 & 658,00 & 703,90 & 934,00 & 873,50 & 809,00 & 851,00 & 876,00 \\
\hline $\mathrm{Ni}$ & 50,00 & n.d. & 120,00 & n.d. & n.d. & 24,00 & 50,00 & 50,00 & 60,00 \\
\hline $\mathrm{Cr}$ & 50,00 & - & 190,00 & - & n.d. & - & 40,00 & 30,00 & 50,00 \\
\hline $\mathrm{Co}$ & 32,00 & 32,00 & 46,00 & 27,00 & 26,00 & 32,70 & 33,00 & 32,00 & 32,00 \\
\hline $\mathrm{Nb}$ & 75,00 & 55,80 & 57,00 & 54,90 & 55,00 & 57,20 & 62,00 & 61,00 & 61,00 \\
\hline $\mathrm{Zr}$ & 371,00 & 300,80 & 286,00 & 337,20 & 299,00 & 313,00 & 304,00 & 301,00 & 303,00 \\
\hline$Y$ & 36,00 & 39,30 & 32,00 & 41,80 & 39,00 & 32,30 & 31,00 & 30,00 & 31,00 \\
\hline $\mathrm{Hf}$ & 8,10 & 7,60 & 6,00 & 8,90 & 6,70 & 7,20 & 6,90 & 6,90 & 6,70 \\
\hline$u$ & 2,00 & 1,70 & 1,30 & 1,60 & 1,30 & 1,30 & 1,40 & 1,40 & 1,30 \\
\hline Th & 5,90 & 4,20 & 3,60 & 4,50 & 4,10 & 3,90 & 4,00 & 3,90 & 3,90 \\
\hline $\mathrm{Pb}$ & 7,00 & 1,50 & 6,00 & 1,40 & n.d. & 0,70 & n.d. & n.d. & n.d. \\
\hline $\mathrm{Ga}$ & 26,00 & 25,40 & 23,00 & 24,60 & 25,00 & 22,10 & 25,00 & 24,00 & 24,00 \\
\hline Sc & 18,00 & 16,00 & 23,00 & 19,00 & 15,00 & 15,00 & 17,00 & 16,00 & 18,00 \\
\hline V & 269,00 & 235,00 & 284,00 & 235,00 & 251,00 & 205,00 & 244,00 & 237,00 & 253,00 \\
\hline $\mathrm{Cs}$ & n.d. & 0,20 & n.d. & 0,20 & n.d. & 0,20 & n.d. & n.d. & n.d. \\
\hline Ta & 4,90 & 3,90 & 3,80 & 4,00 & 4,10 & 4,00 & 4,60 & 4,50 & 4,40 \\
\hline Sn & 4,00 & 3,00 & 3,00 & 3,00 & 6,00 & 3,00 & 4,00 & 3,00 & 3,00 \\
\hline La & 53,00 & 38,40 & 35,30 & 38,50 & 41,70 & 39,10 & 42,90 & 43,40 & 43,10 \\
\hline $\mathrm{Ce}$ & 114,00 & 80,00 & 75,00 & 79,60 & 89,10 & 82,70 & 94,50 & 94,90 & 95,60 \\
\hline $\mathrm{Pr}$ & 14,30 & 10,43 & 9,43 & 10,91 & 11,20 & 11,16 & 12,00 & 12,00 & 11,90 \\
\hline $\mathrm{Nd}$ & 56,70 & 44,50 & 38,00 & 48,00 & 46,90 & 46,80 & 49,70 & 50,20 & 50,60 \\
\hline $\mathrm{Sm}$ & 11,80 & 9,22 & 8,20 & 10,26 & 10,70 & 9,32 & 10,40 & 10,40 & 10,50 \\
\hline Eu & 3,63 & 3,29 & 2,61 & 3,60 & 3,39 & 3,22 & 3,31 & 3,30 & 3,25 \\
\hline $\mathrm{Gd}$ & 10,70 & 9,14 & 7,50 & 9,96 & 9,80 & 8,24 & 8,90 & 9,00 & 9,00 \\
\hline Tb & 1,60 & 1,49 & 1,20 & 1,61 & 1,50 & 1,30 & 1,30 & 1,30 & 1,30 \\
\hline Dy & 8,00 & 7,43 & 6,20 & 7,89 & 8,00 & 6,25 & 6,80 & 6,80 & 6,60 \\
\hline Ho & 1,50 & 1,31 & 1,20 & 1,46 & 1,50 & 1,15 & 1,30 & 1,20 & 1,20 \\
\hline Er & 3,70 & 3,52 & 3,00 & 3,90 & 3,70 & 3,03 & 3,20 & 3,20 & 3,10 \\
\hline $\mathrm{Tm}$ & 0,53 & 0,50 & 0,43 & 0,54 & 0,53 & 0,42 & 0,44 & 0,43 & 0,42 \\
\hline $\mathrm{Yb}$ & 3,10 & 2,81 & 2,50 & 3,23 & 3,10 & 2,32 & 2,60 & 2,70 & 2,60 \\
\hline Lu & 0,48 & 0,42 & 0,39 & 0,45 & 0,48 & 0,34 & 0,41 & 0,41 & 0,39 \\
\hline
\end{tabular}


As rochas efusivas estudadas foram classificadas como basanitos, basaltos alcalinos e hawaítos, com predominância de hawaítos, de acordo com a classificação do diagrama TAS (Middlemost, 1994) (Figura 5).

O conteúdo de álcalis (\% de peso) varia entre $3,04 \%$ e $6,00 \%$. As rochas apresentam afinidade alcalina segundo o limite de alcalinidade definido por MacDonald (1968) no diagrama TAS (Figura 5).
O conteúdo de $\mathrm{MgO}$ das rochas da Ilha São Jorge varia de $4,19 \%$ a $11,74 \%$ e o teor de $\mathrm{SiO}_{2}$ varia de $43,90 \%$ a $48,36 \%$. O MgO foi escolhido como índice de diferenciação (ID) para os diagramas de variação, por ser o óxido com percentual mais amplo para o conjunto de amostras.

$\mathrm{O}$ diagrama $\mathrm{K}_{2} \mathrm{O}$ versus $\mathrm{Na}_{2} \mathrm{O}$ (Figura 6 Middlemost, 1975) indica que o vulcanismo da Ilha São Jorge é de natureza sódica.

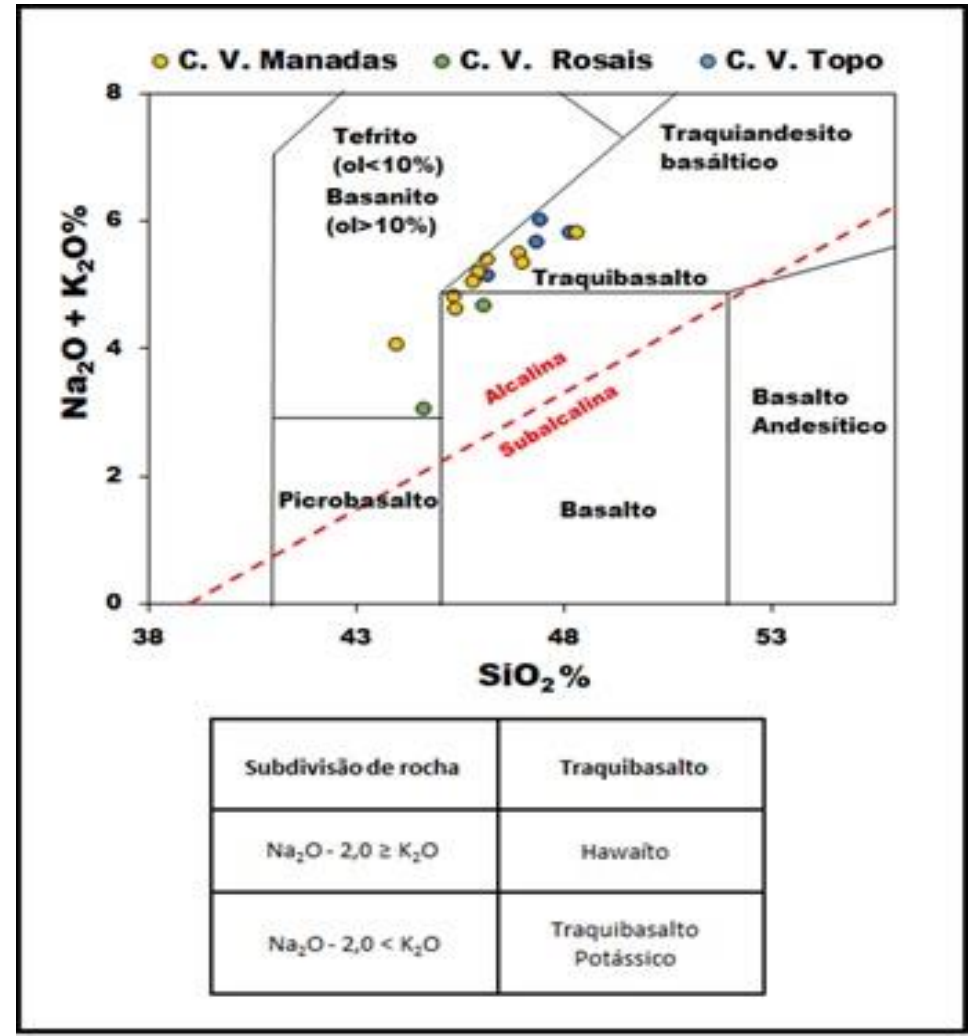

Figura 5 - Diagrama Total-Álcalis versus Sílica (TAS - Middlemost, 1994). Valores em \% de peso após recálculo para $100 \%$ em base anídrica. As rochas da Ilha São Jorge plotam acima do limite de alcalinidade (linha tracejada vermelha) definida por MacDonald (1968). A classificação das rochas é observada no diagrama, mas é necessário considerar os critérios de subclassificação para cada campo: o tefrito tem olivina normativa (ol) < 10\% e o basanito apresenta ol > $10 \%$. $\mathrm{O}$ traquibasalto é subdividido em hawaíto e traquibasalto potássico, como mostra o quadro acima. Segundo esses critérios, as rochas desse trabalho foram classificadas como basanitos e hawaítos. O teor de $\mathrm{MgO}$ varia de $11,74 \%$ a $8,24 \%$ nos basanitos, de $5,73 \%$ a $5,20 \%$ nos basaltos alcalinos e de $8,02 \%$ a $4,19 \%$ nos hawaítos.

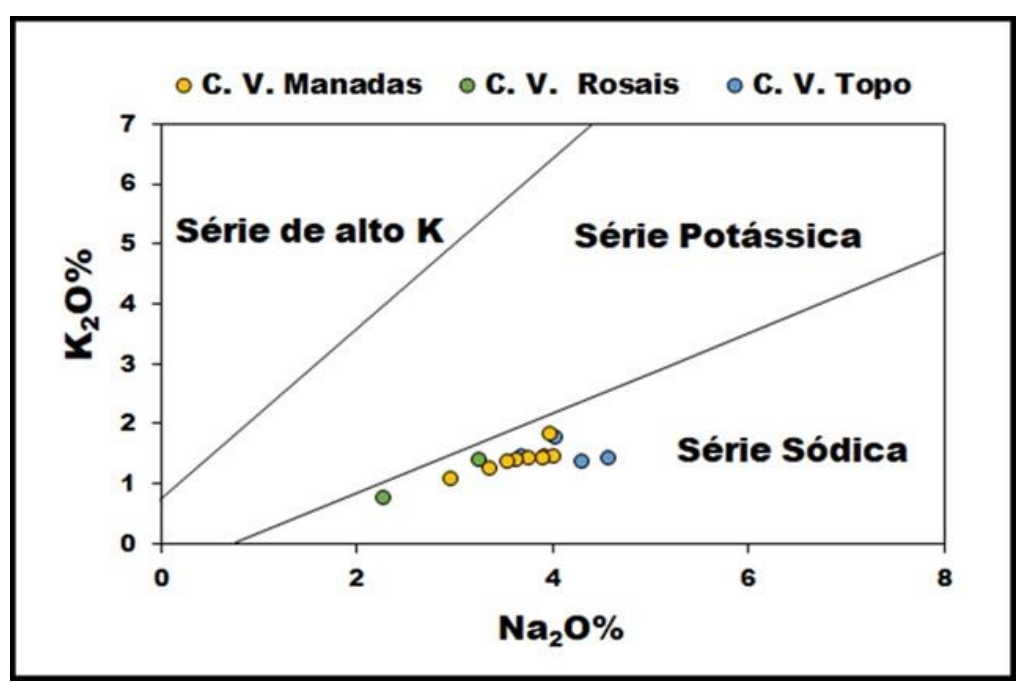

Figura 6 - Diagrama $\mathrm{K}_{2} \mathrm{O}$ versus $\mathrm{Na}_{2} \mathrm{O}$ (Middlemost, 1975) que mostra a natureza sódica das rochas efusivas da Ilha São Jorge. 
Nos diagramas de variação de elementos maiores e menores em relação ao $\mathrm{MgO}$ (Figura 7), $\mathrm{SiO}_{2}, \mathrm{TiO}_{2}, \mathrm{Al}_{2} \mathrm{O}_{3}, \mathrm{Na}_{2} \mathrm{O}, \mathrm{K}_{2} \mathrm{O}$ e $\mathrm{P}_{2} \mathrm{O}_{5}$ apresentam correlação negativa, enquanto o $\mathrm{CaO}$ possui correlação positiva. Observa-se uma inflexão em $\mathrm{MgO} \cong 6,0 \%$, nos diagramas de
$\mathrm{TiO}_{2}$ e $\mathrm{Al}_{2} \mathrm{O}_{3}$. Além disso, há muita dispersão no diagrama de $\mathrm{Fe}_{2} \mathrm{O}_{3}{ }^{\mathrm{t}}$. Os padrões das correlações indicam que a cristalização fracionada de olivina, augita, plagioclásio e minerais opacos é o processo magmático responsável pela geração dos diferentes tipos de rochas.

\section{$\circ$ C.V. Manadas $\circ$ C.V.Topo $\circ$ C.V. Rosais}

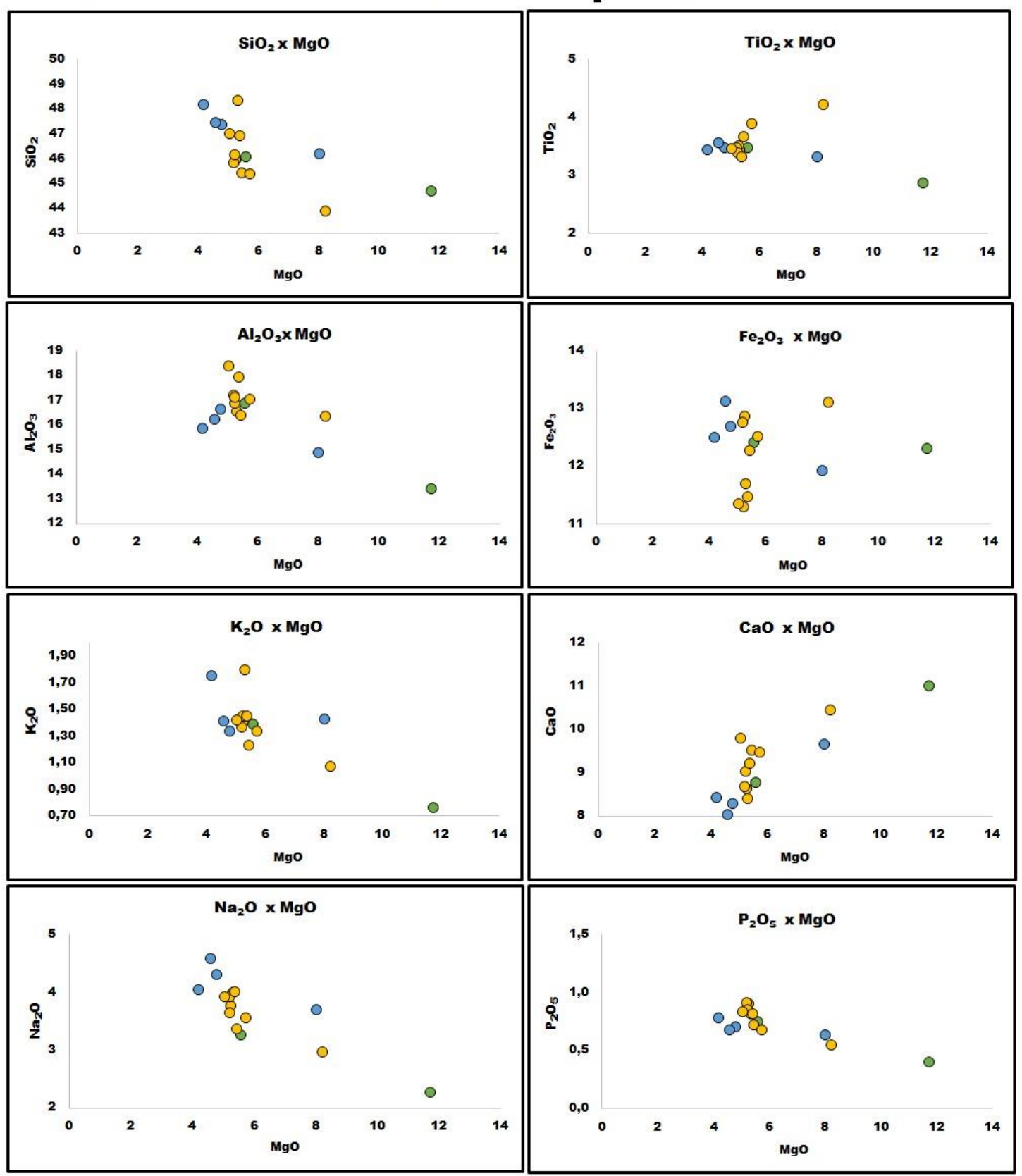

Figura 7 - Diagramas de variação de elementos maiores e menores (\% em peso) versus $\mathrm{MgO}$ (\% em peso), para as rochas efusivas da Ilha São Jorge.

O padrão da correlação dos óxidos com o $\mathrm{MgO}$ é similar para os três complexos vulcânicos da Ilha São Jorge (CVT, CVR e CVM). Pequenas variações podem ser observadas. O CVR apresenta maior concentração de $\mathrm{MgO}(5,58 \%$ a $11,74 \%)$ e de $\mathrm{CaO}(8,77 \%$ a $11,00 \%)$, e menor de $\mathrm{TiO}_{2}(2,88 \%$ a $3,48 \%), \mathrm{Al}_{2} \mathrm{O}_{3}(13,42 \%$ a $16,89 \%), \mathrm{Na}_{2} \mathrm{O}(2,28 \%$ a $3,27 \%), \mathrm{K}_{2} \mathrm{O}(0,76 \%$ a
$1,39 \%)$ e $\mathrm{P}_{2} \mathrm{O}_{5}(0,40 \%$ a $0,75 \%)$, em relação às amostras do CVT e CVM.

Nos diagramas de variação para elementostraço em relação ao $\mathrm{MgO}$ (Figura 8), observa-se que $\mathrm{Ba}$ e $\mathrm{Sr}$ mostram correlações negativas, e uma inflexão em $\mathrm{MgO} \cong 5,0 \%$ pode ser notada no diagrama para Sr. Os elementos $\mathrm{Co}, \mathrm{Sc}, \mathrm{Cr}$ e $\mathrm{Ni}$ apresentam correlações positivas. 
$\circ$ C.V. Manadas ค C.V.Topo คC.V. Rosais

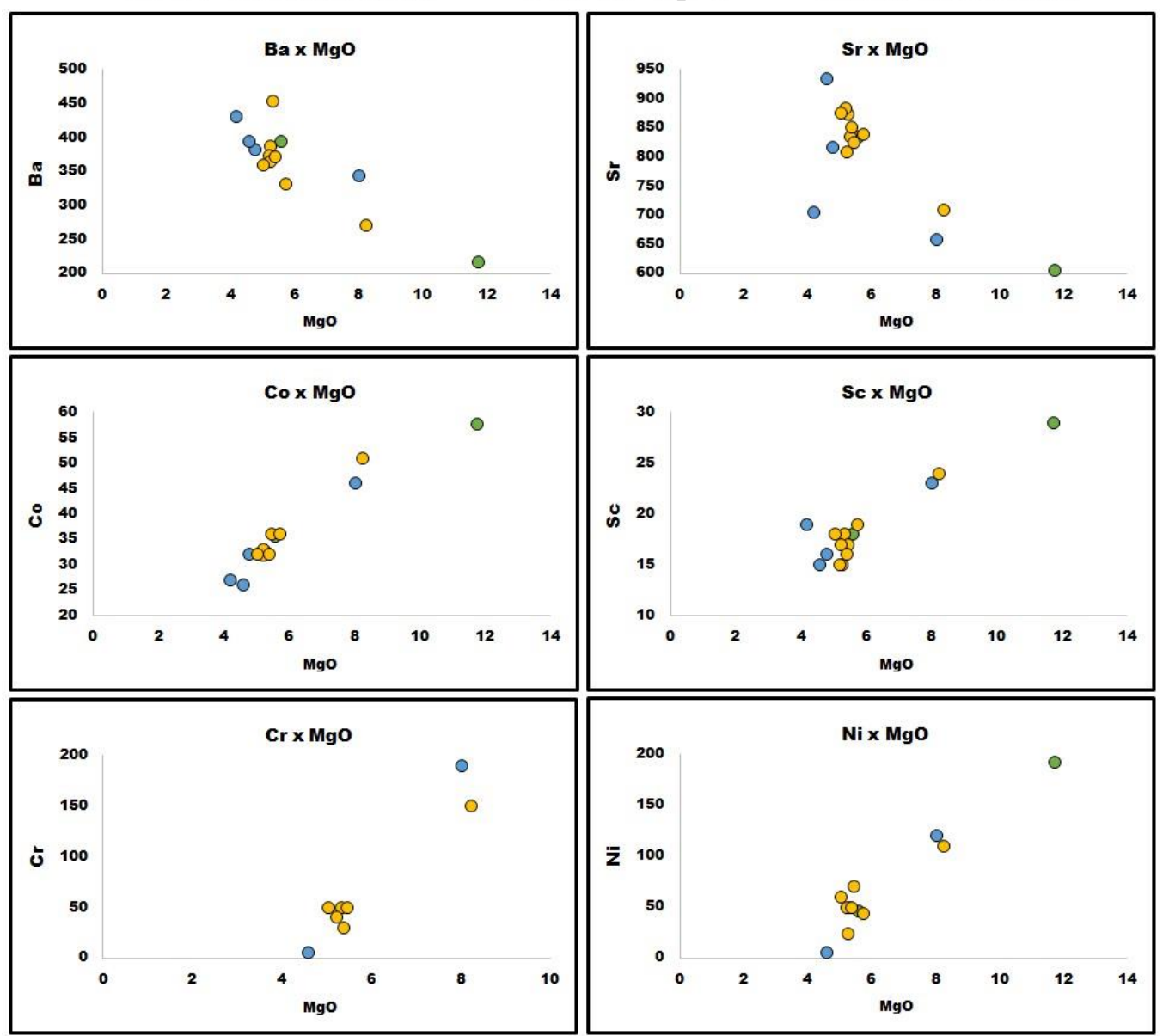

Figura 8 - Diagramas de variação de elementos-traço (ppm) versus $\mathrm{MgO}$ (\% em peso), para as rochas efusivas da Ilha São Jorge.

No diagrama multielementar de elementostraço normalizados pelo manto primitivo segundo Sun \& Mcdonough (1989) (Figura 9), as amostras das três unidades vulcânicas da Ilha São Jorge (CVT, CVR e CVM) apresentam características semelhantes, com enriquecimento de elementos litófilos de grande raio iônico (LILE) e elementos de alto potencial iônico
(HFSE) em relação aos elementos terras raras pesados (ETRP).

As rochas possuem anomalias positivas de $\mathrm{U}$, $\mathrm{Ta}$ e $\mathrm{Sr}$, e anomalias negativas de K. As amostras do CVM apresentam anomalia positiva de Ti. Um basanito (SJ-01/08) da CVR é o menos enriquecido com relação a todos os elementos incompatíveis.

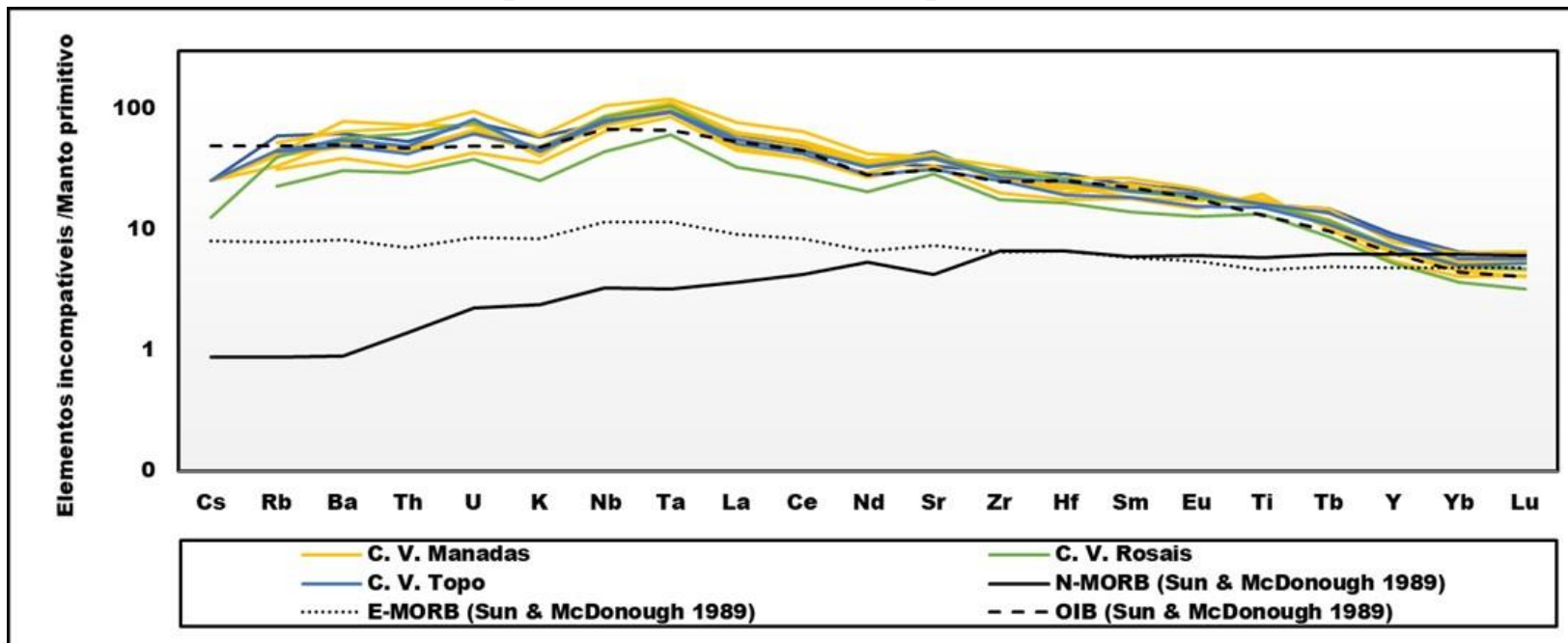

Figura 9 - Diagrama multielementar de elementos-traço das rochas efusivas da Ilha São Jorge, normalizados pelo manto primitivo (Sun \& Mcdonough, 1989). 
O diagrama multielementar de elementos terras raras (ETR) normalizados para os valores do condrito segundo Sun \& Mcdonough (1989) (Figura 10), para as rochas efusivas da Ilha São Jorge, mostra um padrão de enriquecimento em elementos terras raras leves (ETRL) em relação aos ETRP. As amostras de dois hawaítos (CVM - SJ-02/08 e CVT - SJ-04/08) são as rochas mais enriquecidas em ETRL. Todas as amostras apresentam anomalia negativa de Eu. $\mathrm{O}$ padrão observado nas rochas da Ilha São Jorge é semelhante ao padrão dos basaltos de ilha oceânica (OIB), assim como mostra o diagrama da figura 9, corroborando um ambiente geotectônico do tipo intraplaca definido para o Arquipélago dos Açores.

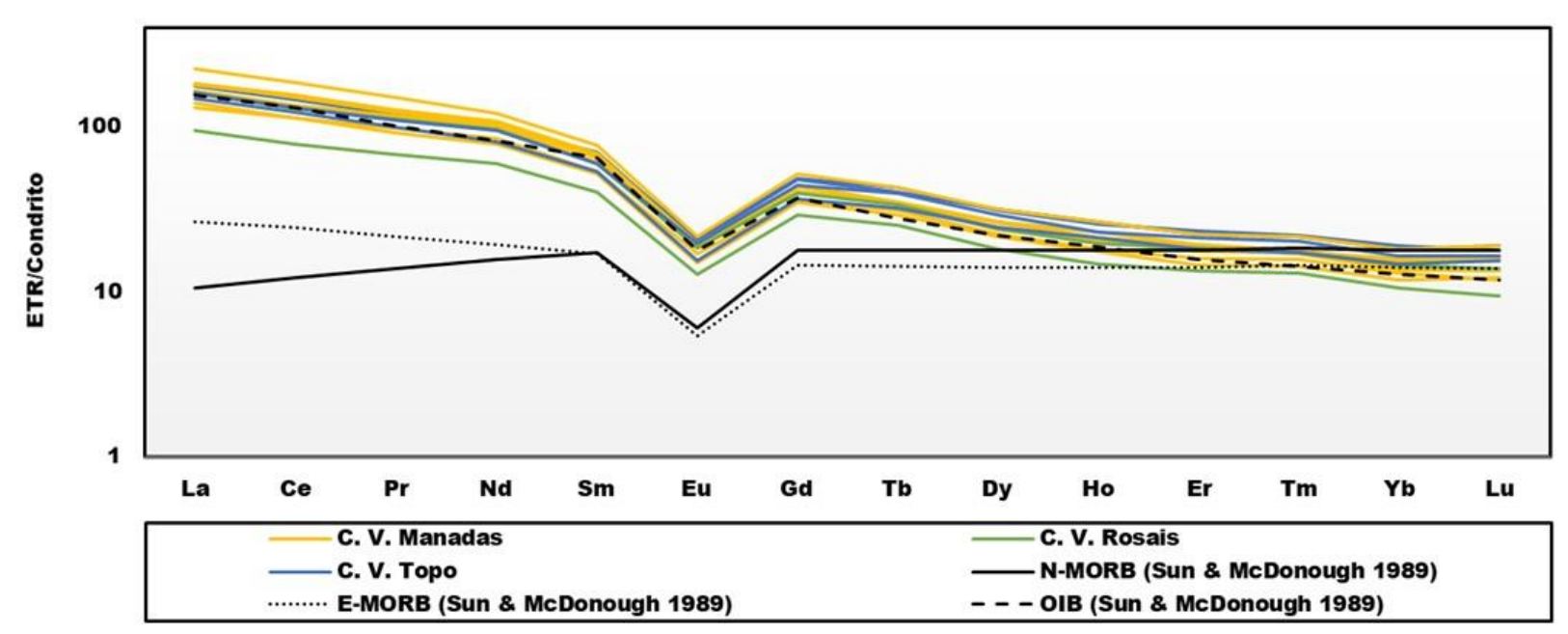

Figura 10 - Diagrama multielementar de elementos terras raras das rochas efusivas da Ilha São Jorge, normalizados para os valores do condrito (Sun \& Mcdonough, 1989).

\section{DISCUSSÕES}

A presença de textura porfirítica é frequente nas rochas vulcânicas da Ilha São Jorge e sugere que, no mínimo, dois estágios de cristalização fracionada ocorreram no líquido magmático. O primeiro ocorreu em alta temperatura, com pequenas taxas de resfriamento, gerando cristais que se formaram e cresceram em um intervalo de tempo específico. A segunda fase permitiu apenas a formação dos cristais da matriz, devido ao resfriamento rápido, corroborando a interpretação de Ribeiro (2011).

A feição de reabsorção, observada com frequência em fenocristais de olivina, augita e plagioclásio (textura sieve), é típica de desequilíbrio relacionada à rápida descompressão do magma, um processo comum na mineralogia de rochas vulcânicas (Nelson \& Montana, 1992; Ribeiro, 2011). Segundo Renjith (2014), essa textura pode ser decorrente da mudança de pressão, temperatura, teor de água e composição do magma.

A textura sieve grossa se desenvolve durante o processo de descompressão, quando o magma subsaturado em água ascende rapidamente (Nelson \& Montana, 1992; Renjith, 2014). Como consequência, a pressão da água do sistema aumenta e a estabilidade do plagioclásio se reduz, causando dissolução (Nelson \& Montana, 1992; Renjith, 2014). A textura sieve fina é formada devido à dissolução parcial dos cristais pré-existentes na câmara, por reação com magma mais quente e rico em $\mathrm{Ca}$, que foi trazido por eventos de recarga. $\mathrm{O}$ processo de reabsorção gera "buracos" na superfície do cristal, devido à dissolução, que podem ser preenchidos por outros minerais, na forma de inclusões (Renjith, 2014).

O embainhamento nas bordas da olivina e do plagioclásio indica que ocorreu uma cristalização precoce dos minerais, os quais posteriormente, entraram em desequilíbrio durante a cristalização fracionada, à medida que a composição do magma evoluiu, resultando em corrosão magmática (Ribeiro, 2011).

A zonação observada em alguns fenocristais de augita e plagioclásio ocorre como resultado de pequenas variações na composição química do mineral, devido à sua incapacidade de manter o equilíbrio químico durante o resfriamento rápido do magma, com variações bruscas de temperatura e pressão (Beier et al., 2006; Ribeiro, 2011). 
A bowlingita é o produto de alteração da olivina, principalmente rica em Mg (Delvigne et al., 1979), sob condições deutéricas tardimagmáticas, resultante da interação com fluidos (Almeida \& Hollanda, 2009).

A borda de reação na kaersutita, formada por minerais opacos (magnetita), pode estar associada a diferentes processos, como desidratação e diminuição da pressão devido à ascensão rápida do magma, ou através do reaquecimento do magma por meio da recarga da câmara magmática, acima do campo de estabilidade do mineral (Rutherford \& Hill, 1993; Nicholis \& Rutherford, 2004; Beier et al., 2006). Ribeiro (2011) sugere que a cristalização da kaersutita ocorreu em níveis mais profundos e que seria um xenocristal trazido à superfície pelo magma hospedeiro. Entretanto, para Nicholis \& Rutherford (2004), a descompressão produz dissolução dos cristais, mas como o material é transportado para longe, devido às altas taxas de difusão, as bordas de reação não se desenvolvem. Nesse caso, para gerar condições para a formação de bordas de reação, a kaersutita precisa estar em profundidade rasa, fora do campo de estabilidade do anfibólio, com transporte suprimido. Dessa forma, as bordas de reação na kaersutita sugerem algum tempo de residência do magma em nível superficial.

Nos diagramas de variação de elementos maiores e menores, o empobrecimento em $\mathrm{CaO}$, observado nas rochas ao longo da evolução magmática, reflete a cristalização de plagioclásio e clinopiroxênio cálcicos. A correlação negativa do $\mathrm{TiO}_{2}$ (seguida pela inflexão em $\mathrm{MgO} \cong 6 \%$ ), além da dispersão no diagrama do $\mathrm{Fe}_{2} \mathrm{O}_{3}{ }^{\mathrm{t}}$ com o $\mathrm{MgO}$ ao longo da diferenciação, indica fracionamento de minerais opacos ricos em FeTi (provavelmente titanomagnetita), marcado principalmente pela diminuição do conteúdo desses elementos em algumas amostras do CVM. A variação do conteúdo de $\mathrm{Al}_{2} \mathrm{O}_{3}$ em relação ao $\mathrm{MgO}$ reflete o fracionamento de plagioclásio, com um empobrecimento de $\mathrm{Al}_{2} \mathrm{O}_{3}$ quando o $\mathrm{MgO}<6 \%$, que é mais acentuado para três amostras do CVT. Essas inflexões de algumas rochas do CVT para o $\mathrm{Al}_{2} \mathrm{O}_{3}$ ocorrem quando o fracionamento de plagioclásio se torna predominante e supera a cristalização de olivina e augita. A correlação negativa de $\mathrm{SiO}_{2}$ com o $\mathrm{MgO}$ é compatível com a cristalização da olivina, enquanto as correlações negativas de $\mathrm{Na}_{2} \mathrm{O}, \mathrm{K}_{2} \mathrm{O}$ e $\mathrm{P}_{2} \mathrm{O}_{5}$ com o $\mathrm{MgO}$ indicam que esses óxidos não foram incluídos em fases importantes durante a evolução do magma. Provavelmente ocorreram dois estágios de fracionamento mineral, como mostra a inflexão de $\mathrm{MgO} \cong 6,0 \%$, com predomínio do fracionamento de olivina e augita para o estágio $\mathrm{MgO}>6,0 \%$ e de plagioclásio e óxidos de Fe-Ti no estágio $\mathrm{MgO}<6,0 \%$.

Nos diagramas de variação de elementostraço, observa-se que $\mathrm{Ba}$ e $\mathrm{Sr}$ mostram correlações negativas com o $\mathrm{MgO}$. Isso sugere que esses elementos não tiveram participações relevantes em estágios avançados da diferenciação magmática. Contudo, algumas amostras apresentam diminuição da concentração de $\mathrm{Sr}$ (quando o $\mathrm{MgO} \cong 5,0 \%$ ), sugerindo que o plagioclásio representa uma fase importante durante os processos de diferenciação dessas rochas. As correlações positivas de Co, $\mathrm{Sc}, \mathrm{Cr}$ e Ni, com a evolução do magma, refletem o fracionamento de olivina e augita.

As rochas do CVT e do CVM são as mais enriquecidas em elementos incompatíveis (Ba, $\mathrm{Sr})$ e as mais empobrecidas em elementos compatíveis (Co e $\mathrm{Sc}$ ), comparando-se às do CVR.

Os padrões observados nos diagramas de variação de elementos maiores, menores e traço podem ser explicados pela cristalização fracionada de olivina \pm augita \pm plagioclásio \pm minerais opacos. Esses dados são coerentes com a caracterização mineralógica das rochas da ilha.

Nas rochas da Ilha São Jorge, o plagioclásio é cálcico e a olivina é magnesiana, sendo que, segundo Ribeiro (2011), o primeiro corresponde a bytownita e labradorita $\left(\mathrm{An}_{81-55}\right)$ e o segundo corresponde a forsterita (Fo87-60).

As características presentes no diagrama multielementar de elementos-traço normalizados em relação ao manto primitivo (Sun \& Mcdonough, 1989), como o enriquecimento em LILE e HFSE com relação aos ETRP, são típicas de ambientes de OIB. A anomalia negativa de $\mathrm{K}$ está relacionada com a composição da fonte. As anomalias positivas de $\mathrm{Sr}$ (em todas as amostras) e de Ti (nas amostras do CVM), refletem, respectivamente, a acumulação de plagioclásio e de minerais opacos. Esse acúmulo de fenocristais ocorre devido ao fluxo magmático e coincide com as texturas glomeroporfiríticas observadas na petrografia de alguns basaltos alcalinos e hawaítos. As anomalias positivas de U e Ta são compatíveis ao magmatismo intraplaca oceânico. Esses dados de elementos-traço sugerem que a 
fonte de OIB da ilha São Jorge é um pouco mais enriquecida nesses elementos incompatíveis do que a média do padrão de OIB (manto do tipo HIMU). Os dados do diagrama de ETR normalizados pelo condrito (Sun \& Mcdonough, 1989) mostram os padrões de distribuição de ETRL mais fracionados em relação aos ETRP, com maior enriquecimento para as amostras do CVM. Essa característica é típica de lavas de ilha oceânica (Machado et al., 2008).

Os padrões das amostras estudadas formam trends subparalelos e são similares aos de rochas resultantes de baixo grau de fusão parcial, e segundo Machado et al. (2008), são originadas de fontes mantélicas enriquecidas em ETR ou de uma fonte com granada. A anomalia negativa de $\mathrm{Eu}$, observada em todas as amostras, sugere fracionamento de plagioclásio.

\section{CONCLUSÕES}

As composições das rochas da Ilha São Jorge variam de basanitos a basaltos alcalinos e hawaítos, os quais pertencem às unidades vulcânicas CVT, CVR e CVM.

Os complexos vulcânicos CVT e CVM apresentam composições mais enriquecidas em relação ao CVR, com enriquecimento em elementos-traço incompatíveis e empobrecimento em elementos-traço compatíveis. Além disso, as rochas do CVT e do CVM são mais evoluídas, com maiores concentrações de $\mathrm{SiO}_{2} \mathrm{e}$ menores de $\mathrm{MgO}$, comparando-se às do $\mathrm{CVR}$.

$\mathrm{O}$ trend evolutivo das rochas da Ilha São Jorge nos diagramas de variação é o resultado da cristalização fracionada de olivina \pm augita \pm plagioclásio \pm minerais opacos. A cristalização ocorreu em dois estágios. O primeiro ocorreu em alta temperatura, com a geração de fenocristais em um intervalo de tempo mais amplo. O segundo permitiu apenas a formação dos cristais da matriz, devido ao resfriamento rápido.

As feições de reabsorção encontradas em fenocristais de olivina, augita e plagioclásio, a textura sieve no plagioclásio, o embainhamento nas bordas de olivina e plagioclásio, a zonação em cristais de augita e plagioclásio, e as bordas de reação na kaersutita, indicam que o magma sofreu descompressão rápida, com variação brusca de temperatura e pressão.
As diferenças encontradas nos padrões de elementos-traço incompatíveis, como a anomalia positiva de Ti nas amostras do CVM e um menor enriquecimento de todos os elementos incompatíveis em um basanito da CVR, sugerem pequenas variações no grau de fusão parcial, durante a geração do magma da Ilha São Jorge.

Os padrões de ETR observados para as rochas da Ilha São Jorge apresentam teores similares, com trends subparalelos, e indicam que as rochas foram geradas por baixas taxas de fusão parcial.

Os dados químicos das rochas da Ilha São Jorge são compatíveis com dados de ambiente geotectônico do tipo intraplaca oceânico (OIB). As lavas de composição basáltica são predominantes, de afinidade alcalina sódica, originadas a partir de um magma mantélico enriquecido.

Trabalhos futuros, com a obtenção da composição isotópica das lavas, contribuirão para o entendimento das heterogeneidades mantélicas e para a discussão da gênese e da evolução dos Açores, sobretudo em relação às divergências existentes entre as composições de rochas da Ilha São Jorge e de rochas das outras ilhas do Grupo Central. Outrossim, a obtenção de dados de química mineral ajudará a identificar alterações composicionais nos minerais, relacionadas às variações de temperatura e pressão.

\section{AGRADECIMENTOS}

Os autores agradecem à Fundação para a Ciência e Tecnologia (Portugal) e à CAPES (Convênio FCT-CAPES 330/13) pelo financiamento do Projeto de Cooperação Bilateral "Estratigrafia e Geoquímica das Sequências Vulcânicas da Ilha da Graciosa e São Jorge - Arquipélago dos Açores".

\section{REFERÊNCIAS}

ABDEL MONEM, A.A.; FERNANDEZ, L.A.; BOONE, G.M. K-Ar-Ages from the eastern Azores group (Santa Maria, Sao Miguel and the Formigas islands). Lithos, v. 8, p. 247-254, 1975.

ALMEIDA, V.V. \& HOLLANDA M.H.B.M. Petrografia, química mineral e litoquímica de diques máficos cambrianos do extremo oriental do estado da Paraíba. Revista Brasileira de Geociências, v. 39, n. 3, p. 580-598, 2009.

AZEVEDO, J.M. \& FERREIRA, M.R.P. The volcanotectonic evolution of Flores Island, Azores (Portugal). Journ. Vulcanol. Geother. Res. V. 156, p. 90-102, 2006.

AZEVEDO, J.M.M.; ALVES, E.I.; DIAS, J.L. Contributo para a interpretação vulcanoestrutural da ilha do Corvo, Açores. Ciências da Terra, $\mathrm{N}^{\circ}$ Esp. v. A5-A8, 2003.

BEIER, C.; TURNER, S.; PLANK, T.; WHITE, W. A preliminary assessment of the symmetry of source composition and melting dynamics across the Azores plume. Geochemistry, Geophysics, Geosystems, v. 11, 2004, doi: 
10.1029/2009GC002833. 2010.

BEIER, C.; HAASE, K.M.; HANSTEEN, T.H. Magma evolution of the Sete Cidades Volcano, São Miguel, Azores. Journal of Petrology, v. 47, p. 1375-1411, 2006.

BEIER, C.; HAASE, K.M.; TURNER, S.P. Conditions of melting beneath the Azores. Lithos, v. 144-145, p. 1-11, 2012.

CHACE, F.M. Abbreviations in field and mine geological mapping. Scientific Communications. Economy Geology, v. 51, p. 712-723, 1956.

DELVIGNE, J.; BISDOM, E.B.A.; SLEEMAN, J.; STOOPS, G. Olivines, their pseudomorphs and secondary products. Pedologie, v. 29, p. 247-309, 1979.

DEMAND, J.; FABRIOL, R.; GERAD, F.; LUNDT, F.; CHOVELON, P. Prospection geothermique, iles de Faial et de Pico (Acores): rapport geologique, geochimique et gravimetrique. Rapport, 65 p., 1982.

FERREIRA, M.P. \& AZEVEDO, J.M. Evolução geológica do arquipélago dos Açores baseada na geocronologia. Seminar Geologia Atlântica, A.P.G. 9, Ponta Delgada (São Miguel, Açores), 1995.

FORJAZ, V.H. \& FERNANDES, N.S.M. Folha "B" da ilha de S. Jorge (Açores) da Carta Geológica de Portugal na escala 1:50 000. Serv. Geol. Portugal. 1970 .

FORJAZ, V.H. \& FERNANDES, N.S.M. Carta Geológica de Portugal na escala de 1:50000. Noticia explicativa das Folhas “A” e "B”, Ilha de São Jorge (Açores). Serv. Geol. Portugal, 32p. 1975.

FRANÇA, Z. Tipicidade Vulcânica do Arquipélago Açoriano. Disp.

em: www.researchgate.net/publication/236174126_Tipicidade_Vu lcanica_do_Arquipelago_Acoriano, 2009.

FRANÇA, Z.; CRUZ, J.; NUNES, J.C.; FORJAZ, V.H. Geologia dos Açores: Uma perspectiva actual. Revista Açoreana, v. 10 140 p., 2005.

GENTE, P.; DYMENT, J.; MAIA, M.; GOSLIN, J. Interaction between the Mid-Atlantic Ridge and the Azores hotspot during the last 85 Myr: Emplacement and rifting of the hotspot-derived plateaus. G3 (4) 10, 8514. 2003.

GEORGEN, J.E. Lithospheric control on the spatial pattern of Azores hotspot seafloor anomalies: Constraints from a model of plume- triple junction interaction. Geophysical Research Letters, v. 38, L19305, 2011.

HILDENBRAND, A.; MARQUES, F.O.; COSTA, A.C.G.; SIBRANT, A.L.R.; SILVA, P.F.; HENRY, B. Reconstructing the architectural evolution of volcanic islands from combined $\mathrm{K} / \mathrm{Ar}$, morphologic, tectonic, and magnetic data: The Faial Island example (Azores). Journal of Volcanology and Geothermal Research, v. 241-242, p. 39-48, 2012.

LARREA, P.; WIJBRANS, J.R.; GALE, C.; UBIDE, T.; LAGO, M.; FRANÇA, Z. ${ }^{40} \mathrm{Ar} /{ }^{39} \mathrm{Ar}$ constraints on the temporal evolution of Graciosa Island Azores (Portugal). Bulletin of Volcanology, v. 76, p. 796, 2014.

LARREA, P.; WIDOM, E.; FRANÇA, Z.; LAGO, M. Petrology of the Azores Islands. Volcanoes of the Azores, Active Volcanoes of the World, https://doi.org/10.1007/978-3-64232226-6_10, 2018.

MACDONALD, G.A. Composition and origin of Hawaiian lavas. In: Coats R. R., Hay R. L. \& Anderson, C. A. (eds.). Studies in volcanology: a memoir in honour of Howel Williams. 23. Geol. Soc. Amer. Mem. V. 116, p. 477-522, 1968.

MACHADO, A., AZEVEDO, J.M.M., ALMEIDA, D.P.M., CHEMALE JR., F. Geochemistry of Volcanic Rocks from Faial Island (Azores). Revista Electrónica de Ciências da Terra, v. 5, p. 1-14, 2008.

MENDES, V.B.; MADEIRA, J.; SILVEIRA, A.B.; TROTA, A.; ELOSEGUI, P.; PAGARETE, J. Present-day deformation in
São Jorge Island, Azores, from episodic GPS measurements (2001-2011). Advances in Space Research, http://dx.doi.org/10.1016/j.asr.2012.10.019. 2013.

MIDDLEMOST, E.A.K. Naming materials in the magma/igneous rock system. Earth Science Review, v. 37, p. 215-224, 1994.

MIDDLEMOST, E.A.K. The basalt clan. Earth Science Reviews, v. 11, p. 337-364, 1975.

NELSON, S.T. \& MONTANA, A. Sieve-textured plagioclase in volcanic rocks produced by rapid decompression. American Mineralogist, v 77, p. 1242-1249, 1992.

NICHOLIS, M.G. \& RUTHERFORD, M.J. Experimental constrains on magma ascent rate for the Crater Flat volcanic zone hawaiite. Geology, v. 32, p. 489-492, 2004.

NUNES, J.C. A actividade vulcânica na ilha do Pico do Plistocénico Superior ao Holocénico: mecanismo eruptivo e hazard vulcânico. Tese (Doutorado), Departamento Geociências, Universidade de Açores, 357 p., 1999.

PACHECO, J.M.; FERREIRA, T.; QUEIROZ, G.; WALLENSTEIN, N.; COUTINHO, R.; CRUZ, J.V.; PIMENTEL, A.; SILVA, R.; GASPAR, J.L.; GOULART, C. Notas sobre a geologia do arquipélago dos Açores. In: DIAS, R.; ARAÚJO, A.; TERRINHA, P.; KULLBERG, J.C. (Eds), Geologia de Portugal, v. 2, Escolar Editora, p. 595-690, 2013. RENJITH, M.L. Micro-textures in plagioclase from 1994 e 1995 eruption, Barren Island Volcano: Evidence of dynamic magma plumbing system in the Andaman subduction zone. Geoscience Frontiers, v. 5, p. 113-126, 2014.

RIBEIRO, L.J.C. Caracterização Petrológica e Geoquímica do Vulcanismo da Ilha de São Jorge, Açores. Tese (Doutorado). Departamento de Geociências, Universidade de Aveiro, Portugal, 275p. 2011

ROSSETTI, M.M.M.; LIMA, E.F.; ROSSETTI, L.M.M.; SCHERER, C.M.; LUZ, F.R.; SOMMER, C.A. Caracterização Morfológica das Lavas Básicas na Erupção de 1580 da Ilha de São Jorge, Açores. In: SIMPÓSIO DE VULCANISMO E AMBIENTES ASSOCIADOS, São Paulo, 2015. Atas...São Paulo, 2015

RUTHERFORD, M.J., \& HILL, P.M. Magma ascent rates from amphibole breakdown: An experimental study applied to the 1980-1986 Mount St. Helens eruptions: Journal of Geophysical Research, v. 98, p. 19,667-19,685, 1993.

SIIVOLA, J. \& SCHMID, R. List of Mineral Abbreviations. Recommendations by the IUGS Subcommission on the Systematics of Metamorphic Rocks, 2007.

SUN, S.S. \& MCDONOUGH, W.F. Chemical and isotopic systematics of oceanic basalts: implications for mantle composition and processes. In: SAUNDERS, A.D. AND NORRY, M.J. (Eds.). Magmatism in ocean basins, Geological Society of London, Special, Publication, v. 42, p. 313-345, 1989

WHITE, W.M.; SCHILLING, J.-G.; HART, S.R. Evidence for the Azores mantle plume from strontium isotope geochemistry of the Central North Atlantic. Nature, v. 263, p. 659-663, 1976.

Submetido em 24 de março de 2019 Aceito em 10 de janeiro de 2020 